Article

\title{
Evolutionary Game of Multi-Subjects in Live Streaming and Governance Strategies Based on Social Preference Theory during the COVID-19 Pandemic
}

\author{
Tinggui Chen ${ }^{1,2, *} \mathbb{C}$, Lijuan Peng ${ }^{1}$, Jianjun Yang ${ }^{3}$, Guodong Cong ${ }^{4}$ and Guoping Li $^{5}$ \\ 1 School of Statistics and Mathematics, Zhejiang Gongshang University, Hangzhou 310018, China; \\ Cherrylijuanpeng@163.com \\ 2 Academy of Zhejiang Culture Industry Innovation \& Development, Zhejiang Gongshang University, \\ Hangzhou 310018, China \\ 3 Department of Computer Science and Information Systems, University of North Georgia, \\ Oakwood, GA 30566, USA; Jianjun.Yang@ung.edu \\ 4 School of Tourism and Urban-Rural Planning, Zhejiang Gongshang University, Hangzhou 310018, China; \\ cgd@mail.zjgsu.edu.cn \\ 5 Zhejiang Liziyuan Food Co., Ltd., Hangzhou 310018, China; winnerwon@163.com \\ * Correspondence: ctgsimon@mail.zjgsu.edu.cn
}

check for updates

Citation: Chen, T.; Peng, L.; Yang, J.; Cong, G.; Li, G. Evolutionary Game of Multi-Subjects in Live Streaming and Governance Strategies Based on Social Preference Theory during the COVID-19 Pandemic. Mathematics 2021, 9, 2743. https://doi.org/ $10.3390 /$ math 9212743

Academic Editors: Elena Gubar, Denis Fedyanin and Krzysztof J. Szajowski

Received: 17 August 2021

Accepted: 26 October 2021

Published: 28 October 2021

Publisher's Note: MDPI stays neutral with regard to jurisdictional claims in published maps and institutional affiliations.

Copyright: (c) 2021 by the authors. Licensee MDPI, Basel, Switzerland. This article is an open access article distributed under the terms and conditions of the Creative Commons Attribution (CC BY) license (https:/ / creativecommons.org/licenses/by/ $4.0 /)$.

\begin{abstract}
After the outbreak of the COVID-19, offline consumption has been significantly impacted For the sake of safety, online consumption has become the most common manner, and this has generated e-commerce, which not only breaks the spatio-temporal or regional restrictions, but also conforms to the normal economic development needs for epidemic prevention and control. However, this new business model causes problems such as the shortage of post-sales service, false publicity, and uneven quality of live streaming anchors, seriously affecting the interests of consumers. Therefore, it is urgent to strengthen the management of the chaos of live streaming. This study focuses on exploring the problems and the behavioral strategies of stakeholders in the governance process. The paper obtained online user comments by python, and used topic clustering and subject extraction methods to dig out the problems and related multiple subjects in live streaming at first. Secondly, the theory of social preference was introduced to construct an evolutionary game model among multiple subjects, and how to guide the behavioral decision-making of multiple subjects to standardize and rationalize was studied, so as to control the problem of live streaming. Finally, simulation experiments were conducted and the results demonstrated that: (1) Compared with strengthening the reciprocal preference of the government, live streaming platforms, and consumers, changing the individual's altruistic preference is more effective in controlling the chaos of live streaming; (2) weakening the platform's altruistic preference for anchors is conducive to creating a good live streaming environment; and (3) changing consumers' altruistic preference or reciprocal preference is less effective in promoting the governance of the live streaming environment.
\end{abstract}

Keywords: live streaming; social preference theory; evolutionary game; environmental governance; COVID-19

\section{Introduction}

At the end of 2019, sweeping most countries in the world, COVID-19 seriously affected people's daily production and life. Targeted at epidemic prevention and control, it is necessary to reduce the original offline trading activities. In turn, a new format of the e-commerce live streaming was born. Based on 5G, VR and other state-of-art information technologies, it has the characteristics of timeliness, interactivity, and immersion, which can greatly satisfy the consumer needs, enrich the current marketing model to a large extent, and increase the flexibility and expand space for economic development. In addition, live streaming can lower offline contact, avoid the spread of the virus, help resume work and 
production under the normalization of epidemic prevention and control, and meet the consumption and emotional needs of the public as well. Based on this, the home-based live streaming meets people's consumption needs under COVID-19, and becomes a new intermediary [1]. According to statistics from the Ministry of Commerce of China, there was more than 4 million times of live streaming nationwide in the first quarter of 2020 . The 45th Statistical Report on China's Internet Development showed that as of March 2020, the number of live streaming users reached 265 million, accounting for $37.2 \%$ of online buyers and for $47.3 \%$ of live streaming users. Due to the rapid development of the Internet, e-commerce live streaming has developed rapidly. It is expected to reach 1995 billion RMB Yuan by the end of 2021, and the penetration rate in the e-commerce market will reach $14.3 \%$. However, the emerging marketing model of live streaming has also exposed some limitations as it develops rapidly. According to the Survey Report on Consumption of Live Streaming Products currently released by the Beijing Consumers Association, out of 30 samples, 9 were suspected of having license information disclosure issues, 3 were suspected of having false propaganda issues, and 1 did not implement the "seven-day return without reason". Based on this, digging out the existing problems of live streaming and proposing corresponding governance measures will not only safeguard the legitimate rights and interests of consumers, but also promote the sound and healthy development of the social economy. This paper aims to explore the internal mechanism of the environmental governance strategy of live streaming, which has important theoretical and practical significances.

At present, there are limited studies on the problems and governance strategies of live streaming. Most of the studies are mainly combining communication [2], psychology [3], and other related fields to conduct qualitative analysis of the phenomenon. Some scholars also use Evolutionary Game Theory [4] to carry out their study. However, qualitative methods are mostly based on personal experiences, which are subjective and one-sidedness. Quantitative methods are based on the assumption of "rational economic individual" and short of the internal characteristics [5]. Generally speaking, social preference is an innate social attribute of human, and the assumption of individual sufficient rationality in economics does not apply to real situations. At the same time, based on users' online comment data of live streaming on the internet platform, the subjects related to live streaming transaction and governance process are excavated. Compared with the subject directly analyzed by "stakeholder theory" in the past, it is closer to the actual situation that consumers encounter in live streaming [6]. In addition, it reduces the participation of irrelevant subjects in the discussion. In addition, by mining consumers' online comments, we can deeply analyze the interest game points and game processes among related subjects to prepare for building an evolutionary game model among multiple subjects. Therefore, this paper is based on the users' online comment data on the live streaming platform, digging out the issues and related subjects mentioned by consumers, and then analyzing the role of different subjects in the governance of the live streaming. With "government" and "live streaming platform" as the key nodes, the live streaming governance process is divided into the "promotion stage" and the "transaction stage". On this basis, the social preference theory is introduced to construct the relationship among the various entities in the live streaming governance promotion stage and the live streaming transaction stage. In the game process, the evolutionary game of each subject is used to explore how to guide the subject's behavioral decision-making to a standardized development, so as to solve the problems mentioned by consumers in the live streaming. Finally, through simulation, the influence of the degree of individual altruistic preference as well as the degree of reciprocity preference on the behavioral strategies of each analysis in the governance process of live streaming environment is discussed.

The main contributions of this paper are as follows: firstly, most of the existing evolutionary game studies use the "interest-related theory" to qualitatively analyze the evolutionary game process among different subjects. However, this study uses the method of subject mining instead of the qualitative analysis of the stakeholders, which is closer to 
real life and enriches the methods of obtaining the sources of evolutionary game subjects. Secondly, most of the existing research on evolutionary game is based on the premise of traditional economics, which lacks the consideration of individual prosocial behavior, i.e., individual social preference. In this study, individual social preferences are introduced to construct an evolutionary game model among subjects, and the changes of interests among subjects are considered from a new perspective, which is closer to people's trading behavior in the real market economy environment. The conclusion is more referential for government governance. Thirdly, the existing research on live delivery mainly adopts qualitative analysis method, and most scholars mainly analyze the existing problems of live delivery by personal experience or cases, but do not summarize the existing problems from a quantitative perspective. In this study, text mining technology is used to quantitatively analyze the online comment information released by the public. In addition, this paper discusses and summarizes the existing problems of live delivery from the public perspective, which enriches the existing research on live delivery.

The structure of this paper is as follows: Section 2 is the literature review; Section 3 is the research framework of the paper; Section 4 uses co-occurrence analysis and topic clustering methods to study the issues and related subjects mentioned in the online reviews of live streaming products; Section 5 introduces the social preference theory to analyze the evolutionary behavioral decision-making of multi-subjects in live streaming; Section 6 is the discussions about simulation results; Section 7 is the conclusions of the whole paper and the prospects of work in the future.

\section{Literature Review}

Based on Internet platforms, stores or professional anchors use live streaming technology to provide close-range product display, reply service, and shopping guide. It breaks through the limitations of the traditional offline sales model and is a new marketing method. At the same time, live streaming has greater randomness, the supervision system is not perfect, and there are some other problems such as false publication and traffic fraud. At present, research on live streaming mainly focuses on two aspects: One is to analyze the impact of the marketing model of live streaming on consumers' purchase intentions, and the other is to explore the problems that occur in live streaming and corresponding countermeasures.

At present, many scholars have conducted research on consumers' purchasing intentions in live streaming. Some typical literatures are as follows: According to the S-O-R model, Wang [7] constructed a model of the influence of live webstars on consumers' purchase intention, and analyzed the characteristics of live network celebrities on consumer trust and purchase intention of the impact. Liu et al. [8] constructed a framework model for the formation mechanism of consumers' purchase intention under the influencer marketing, which included three main categories (namely consumer cognition, consumer emotion, and consumer intention), and nine corresponding subcategories. This model found that the characteristics of the source for Internet celebrity information and consumers' personal level had a significant impact on consumers' purchase intention. In addition, building a theoretical model from the perspective of IT affordance, Sun et al. [9] examined how live streaming influenced social commerce customers' purchase intentions in China. Their results showed that visibility affordance, metavoicing affordance, and guidance shopping affordance could influence customer purchase intention through live streaming engagement. Apiradee et al. [10] proposed a comprehensive framework to examine the relationships among customers' perceived value of live streaming, customer trust, and engagement. Symbolic value was found to have a direct and indirect effect via trust in sellers on customer engagement, while utilitarian and hedonic values were shown to affect customer engagement indirectly through customer trust in products and trust in sellers sequentially. Addo et al. [11] investigated how customer engagement in live-streaming digital marketing affected purchase intentions. Their study introduced a new perception of measuring customer engagement in live-streaming digital marketing and called for 
further research into this new paradigm of social commerce to promote business and service provisions even with the restrictions of COVID-19. Jiang et al. [12] developed a live e-commerce supply chain pricing model with online influencers as retailers by which they investigated the effects of consumers' impulsive consumption behavior and satisfaction. Their study analyzed the impact of consumers' impulse purchases on both manufacturers and retailers, and separately, on supply chains. Apiradee et al. [13] analyzed Facebook data of live streaming sellers to assess the nature and extent of engagement metrics, and delineated the dynamic, interactive live streaming sales process. Building upon attachment theory and socio-technical approach, Li et al. [14] developed a theoretical model to understand how live streaming service affected the user stickiness through users' attachment, which was tested by using 425 live streaming shopping platform's users. The results showed that technical factors (synchronicity and vicarious expression) and social factors (interaction and identification) positively affected emotional attachment to streamers and platform attachment respectively, which in turn increased the user stickiness. Ma [15] used a questionnaire to collect data from 339 Chinese consumers and structural equation modeling to analyze data in AMOS 24. The results showed that experience-focused shopping orientation mediated the relationships among perceived enjoyment, self-presentation, social interaction, and live-stream shopping intentions. The above-mentioned literature mostly uses questionnaires and other methods to study consumer behavior intentions in live streaming, but the target group and research scope of such methods have certain limitations. In fact, live streaming is a marketing model, and most consumers will express their consumption experience through the Internet platform, which meaning that consumers' online comments contain more information and have a wider target group. Therefore, this paper uses consumer review information on live streaming on major Internet platforms as the data source for the research.

In addition, most scholars believe that disorderly development and management chaos are still the main issues of the live streaming industry, especially in terms of social governance, network supervision, and moral construction. They also analyze how to manage chaos in the industry from the perspective of the characteristics and development process of the live streaming industry [16]. For example, Xia et al. [17] found that many college students had a low level of understanding of the risks of shopping. Therefore, in order to better enable college students to avoid risks in the process of live shopping, college students could take measures to retain electronic invoices or proof of their purchase while merchants could improve payment security levels. Yan et al. [18] analyzed the problems of live streaming from both the consumer and supply sides, and believed that with the reduction of the epidemic prevention and control level as well as the restoration of social order, the carnival fever of live streaming would gradually recede. Based on the premise of sufficient statistical data, Huang [19] analyzed the defects and problems of live commerce, such as the lack of credit field of the streamer, the ambiguity of industry threshold, and the weakness of regulation. According to general business laws, the author proposed corresponding countermeasures: supervision departments, live streaming platforms, and consumers need to cooperate in supervising. Based on the current development status of e-commerce live broadcasting in China, Hou [20] predicted the development prospects of e-commerce live broadcasting on the basis of analyzing the successful elements, pros and cons of e-commerce live broadcasting. Xia et al. [21] pointed out that false data, the vague definition of anchors identity and behavior nature, undefined consumer rights, and the live broadcast platform without supervised were the main problems in the current live streaming industry. Therefore, it was urgent to speed up the revision and formulation of special laws and regulations. Based on the Evolutionary Game Theory, Li et al. [22] constructed a game model among the main stakeholders of live streaming, namely, the network supervision department, the live streaming platform, and users. The results showed that the strength of the standardization development of the live streaming platform was in line with the supervision departments. The penalties were in an inverted U-shaped relationship and were positively related to the incentives, and the user's guiding role would 
be marginally diminishing as the platform's incentives increase. The above literatures mainly adopt qualitative methods to analyze the problems and governance strategies in the live streaming of goods, or simulate the game process in the live streaming through traditional theoretical economic models. However, individuals have preference, and the existing literatures rarely consider the integration of social preference theory to discuss the game process of multi-subject governance of live streaming. Regarding the public opinion topics that it aroused on the Internet, there is no literature to discuss it in a quantitative way. Therefore, this paper conducts quantitative research on the topic of live streaming of public opinion such as semantic analysis and topic clustering [23], and introduces social preference theory to discuss how to rationalize and standardize the evolutionary behavior of multiple subjects in the live streaming delivery, so as to achieve the effect of live streaming delivery management.

All in all, although the existing literatures have conducted studies on the marketing model and management of live streaming problems, most of them use traditional questionnaires to obtain data, or use theoretical economic models to discuss governance strategies for live streaming issues, which are not sufficient to explore the online comment information of users on the Internet about live streaming. Based on this, this paper used the online reviews of live streaming to dig out the issues that users are more concerned about and interest subjects at first; secondly, according to the different nature of the subjects, the governance process of live streaming was divided into two stages: promotion and transaction stags. The multi-subjects evolutionary game model of preference theory $=$ was constructed, and how to guide the development of the behavioral strategies of multi-subjects to be standardized and rational was also explored so as to control live streaming; finally, the impacts of different social preference intensities on the evolution of behavioral strategies were studied through simulation analysis.

\section{Research Framework}

This paper first collected the comments on "live streaming" from 6 platforms: Tianya Community Forum, Sohu.com, Tencent.com, IFeng.com, Netease.com, and Weibo during the period from 19 May 2020 to 19 May 2021. By information entropy, co-occurrence matrix and subject extraction, the paper extracts the key information in the comments so as to get the interest game points among the subjects. In addition, the repeated dichotomy is used to classify it by subject, extract the main body according to the classified subject content, so that netizens mention more issues and different subjects involved in the live streaming. In order to solve the problems of live streaming mentioned by netizens, according to the interest subjects and the interest game points among the subjects obtained by online comment mining, the governance process of live streaming is divided into two stages: promotion and transaction stages, and a multi-subject Evolutionary Game model of these two stages is constructed, respectively. At the same time, taking the existence of different preferences of the subject's behavior into account, the social preference theory is introduced to discuss the evolutionary game process of the subjects in the process of live streaming. Subsequently, simulation experiments are used to analyze how the social preference of different subjects will affect the development of their behavior strategies to be more conducive to the governance of live streaming. The research framework of this paper is shown in Figure 1. 


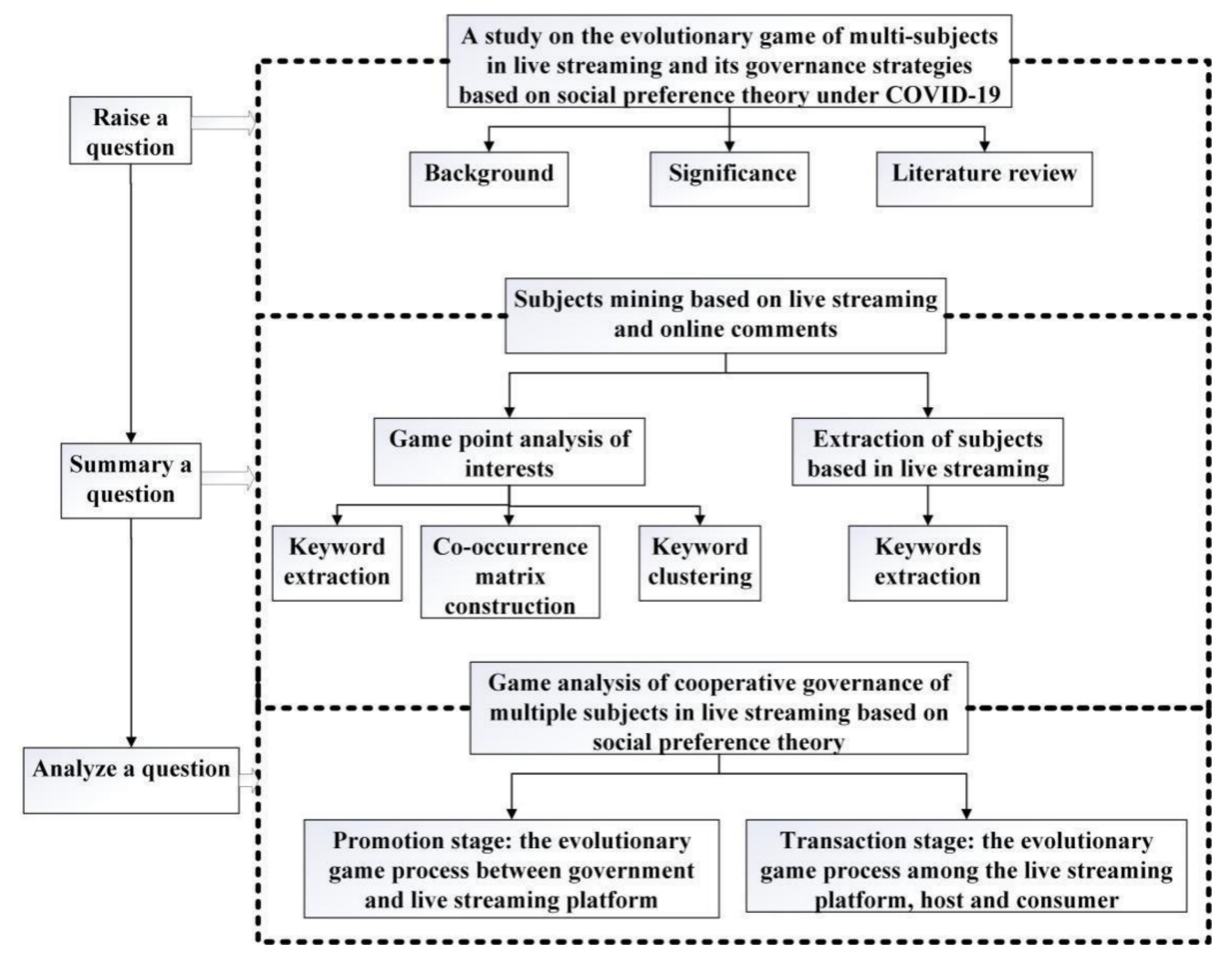

Figure 1. Research framework.

\section{Subjects Mining Based on Live Streaming and Online Comments}

Live streaming has achieved explosive growth in a short period of time with a lowthreshold, low-risk, and high-yield sales model. In particular, the outbreak of the epidemic has resulted in and further boosted the era of live streaming for all people. Live streaming has become an important way for people's consumption. However, there are also many problems with this model. Therefore, in order to analyze the public opinion incidents caused by "live streaming" in recent years, the following classifies the content of the topics that netizens' comments on the Internet, and finds out the key topics that are mentioned more and the related subjects involved. Through topic classification, it analyzes the interest game points among subjects.

\subsection{Interest Game Point Based on Live Streaming Topic}

News webpages, online forums, blogs, and Weibo are the main media that carry live streaming. Therefore, this paper uses python to crawl 120 topics related to "live streaming" on the Tianya.com, Sohu.com, Tencent.com, IFeng.com, Netease.com, and Weibo with a total of 66,217 comments from netizens. In order to get the interest game points among the subjects in the topic of live delivery, we classify the scattered comments and find the interest points related to consumers' rights and interests from the classification results. Each topic is treated as a txt document (the word "document" is used below to represent "topic"). Key words involved are "live streaming", "E-commerce live streaming", "live streaming specifications", "live streaming issues", and so on.

\subsubsection{Keywords Extraction}

The NLPIR word segmentation system [24] is used to segment the collected topics related to "live streaming" and the comment information of netizens, the keywords in the information are extracted, and the frequency of each keyword is counted. According to the extracted 1780 keywords, the total frequency of the keywords appearing in all documents is calculated, and the keywords with the total frequency less than 4 are eliminated. Finally, 
900 keywords are obtained. Among them, there are still words that have a low degree of relevance to the subject of the document. In order to further extract important keywords, the information entropy method is used to measure the information importance of the 900 keywords obtained. In information theory, information entropy is a metric of information uncertainty, which can determine the amount of information provided by words, i.e., the degree of contribution of words regarding determining document semantics (research content) [25], and its calculation formulas are:

$$
\begin{aligned}
& p\left(\text { doc }_{j} \mid \text { term }_{i}\right)=t f_{i j} / g f_{i} \\
& H(\text { doc })=-\sum_{j} p\left(\text { doc }_{j}\right) \log _{2} p\left(\text { doc }_{j}\right) \\
& =-\sum_{j} \frac{d l_{j}}{s g f} \log _{2} \frac{d l_{j}}{s g f} \\
& G W_{i}=1-\frac{H\left({\text { doc } \left.\mid \text { term }_{i}\right)}\right.}{H(\text { doc })}=1+\frac{\sum_{j} p\left(\text { doc }_{j} \mid \text { term }_{i}\right) \log _{2} p\left(\text { doc }_{j} \mid \text { term }_{i}\right)}{H(\text { doc })}
\end{aligned}
$$

where $\operatorname{term}_{i}$ represents word $i, t f_{i j}$ represents the frequency of word $i$ in document $j$, gf $f_{i}$ represents the total frequency of word $i$ in all document, $s g f$ represents the total frequency of all words in the document set, $s g f=\sum_{i=1}^{m} g f_{i}, d l_{j}$ represents the length of document $j$, i.e., the total vocabulary in document $j$. Formula (1) calculates the conditional probability of word $i$ appearing in document $j$, formula (2) calculates the information entropy of the document, and formula (3) calculates the global entropy weight of word $i$. The word selection with information entropy uses $G W_{i}$ to select analysis words, sorts them in descending order of $G W_{i}$ value, and selects the first $N$ words as analysis words. The higher the global entropy weight is, the greater the amount of information representing the vocabulary will be, meaning that vocabulary is the core research topic of the field and an important concept of domain information. The analysis of these vocabularies can better reflect the characteristics of the field.

The entropy values of the above 900 keywords are calculated, and cumulative contribution rate of the entropy value is adopted to filter noise words. Only nouns, verbs, and adjectives are kept. Finally, 237 keywords are selected, whose entropy values account for $80 \%$ of the total entropy, and the top 10 keywords of information entropy are shown in Table 1.

Table 1. Top10 entropy value of keywords.

\begin{tabular}{ccc}
\hline No & Keywords & Frequency \\
\hline 1 & live streaming & 2143 \\
\hline 2 & anchor & 430 \\
\hline 3 & platform & 260 \\
\hline 4 & consumer & 150 \\
\hline 5 & supervision & 127 \\
\hline 6 & Li Jiaqi & 99 \\
\hline 7 & product & 88 \\
\hline 8 & online transaction & 87 \\
\hline 9 & star & 80 \\
\hline 10 & marketing & 74 \\
\hline
\end{tabular}

The 237 keywords in Table 1 have the same root words and synonyms. The Cosine coefficient is used to calculate the similarity relationship among words, and the similar 
words are placed in the same category. Subsequently, a total of 117 keywords are combined. The results are shown in the Table 2.

Table 2. Summarize similar keywords (some words).

\begin{tabular}{|c|c|c|}
\hline No & Synonyms & Combined Name \\
\hline 1 & $\begin{array}{l}\text { Slow live streaming, live streaming, Taobao live streaming, live } \\
\text { streaming chaos, web live streaming, live streaming list, official live } \\
\text { streaming, web live marketing, live marketing, live marketing } \\
\text { behavior, live marketing activities, live streaming operators, online } \\
\text { trading, online trading activities, live marketing personnel, live } \\
\text { streaming marketing platform, live streaming base, mixed live } \\
\text { streaming, web live streaming industry, live streaming industry }\end{array}$ & live streaming \\
\hline 2 & $\begin{array}{l}\text { Customers, consumers, impulsive consumption, consumption, online } \\
\text { consumption, protecting consumers, consumer rights, consumers' } \\
\text { legal rights, consumer rights protection, legal rights }\end{array}$ & $\begin{array}{l}\text { protecting } \\
\text { consumers }\end{array}$ \\
\hline 3 & $\begin{array}{l}\text { Local economic development, economy, fan economy, economic } \\
\text { development, digital economy, live streaming economy, promotion of } \\
\text { county economy, county economy, rural women's economy }\end{array}$ & $\begin{array}{c}\text { economic } \\
\text { development }\end{array}$ \\
\hline 4 & Rural revitalization, help rural revitalization, rural & rural revitalization \\
\hline 5 & $\begin{array}{l}\text { Poverty alleviation areas, poverty alleviation, poverty alleviation, } \\
\text { counterpart assistance, cooperation between the east and the west }\end{array}$ & poverty alleviation \\
\hline 6 & Cadres, leading cadres, officials & officials \\
\hline 7 & $\begin{array}{c}\text { Celebrity, idol, anchor, head anchor, celebrity anchor, team anchor, } \\
\text { opinion leader, internet marketer }\end{array}$ & anchor \\
\hline 8 & $\begin{array}{l}\text { Live streaming user scale, users, web live streaming users, masses, } \\
\text { people, minors, netizens }\end{array}$ & live streaming user \\
\hline 9 & $\begin{array}{c}\text { Supply chain integration, supply chain, suppliers, distributors, } \\
\text { logistics and distribution }\end{array}$ & $\begin{array}{l}\text { live streaming } \\
\text { logistics }\end{array}$ \\
\hline 10 & Monetization ability, ability, profit acquisition, start-up fee, profit & $\begin{array}{l}\text { live streaming } \\
\text { profit }\end{array}$ \\
\hline
\end{tabular}

\subsubsection{Construction of Co-Occurrence Matrix}

In order to analyze the correlation between keywords and each topic collected, the co-occurrence analysis method is used to construct the "keyword-document" co-occurrence matrix. Firstly, formula (4) proposed by Salton and Buckley [26] is used to weight 117 keyword frequencies, and the "keyword-document" weighted frequency matrix is calculated:

$$
W_{i j}=\frac{t f_{i j} \times \log \left(\frac{N}{n_{k}}\right)}{\sqrt{\sum_{m=1}^{T}\left(t f_{m j}\right) \times \log \left(\frac{N}{n_{m}}\right)^{2}}}
$$

where $j$ represents document, $i$ and $m$ represent keywords, $t f_{i j}$ is the frequency of the $i$ keyword in the $j$ document. $N$ is the total number of document, $n_{k}$ is the number of document containing the $i$ keyword, $T$ is the total number of keywords. The rows of the "keyword-document" matrix correspond to different keywords, and the columns correspond to different documents. The element in the matrix is the weighted frequency $W_{i j}$ of the $i$ keyword appearing in the $j$ document. The results are shown in Table 3: 
Table 3. "Keyword-document" matrix.

\begin{tabular}{cccccccc}
\hline & Docu 1 & Docu 2 & Docu 3 & Docu 4 & Docu 22 & Docu 23 & Docu 24 \\
\hline Taobao & 0.5790 & 0 & 0 & 0 & 0.2528 & 0.2699 & 0 \\
\hline Li Jiaqi & 0 & 0 & 0.4046 & 0 & 0.3629 & 0.4145 & 0 \\
\hline Live streaming & 0 & 0.0214 & 0.0256 & 0.0241 & 0.0229 & 0.0262 & 0.0280 \\
\hline Official & 0 & 0 & 0.5986 & 0 & 0 & 0 & 0.5189 \\
\hline $\begin{array}{c}\text { Local economic } \\
\text { development }\end{array}$ & 0 & 0.6626 & 0 & 0 & 0.7110 & 0 & 0.7750 \\
\hline $\begin{array}{c}\text { Rural } \\
\text { revitalization }\end{array}$ & 0 & 0.3086 & 0 & 0 & 0 & 0.2968 & 0 \\
\hline Product quality & 0 & 0 & 0 & 0.3788 & 0.3981 & 0.3680 & 0.4109 \\
\hline
\end{tabular}

Based on the "keyword-document" matrix, the maximum information coefficient (MIC) of two keywords [27] is calculated to construct the co-occurrence matrix of subject words. MIC is a new method proposed in recent years to identify the degree of connection between two variables in big data sets, which can comprehensively and accurately measure the linear and nonlinear relationships between variables. Compared with the traditional co-word strength index, the maximum information coefficient between words can better reflect the similarity between subject words [28]. The result of co-occurrence matrix is shown in Table 4.

Table 4. Co-occurrence matrix of subject words.

\begin{tabular}{cccccccc}
\hline & Taobao & Li Jiaqi & $\begin{array}{c}\text { Live } \\
\text { Streaming }\end{array}$ & Official & $\begin{array}{c}\text { Local Economic } \\
\text { Development }\end{array}$ & $\begin{array}{c}\text { Rural Revi- } \\
\text { talization }\end{array}$ & $\begin{array}{c}\text { Product } \\
\text { Quality }\end{array}$ \\
\hline Taobao & 0.0889 & 0.0017 & 0.0331 & 0.0006 & 0.0002 & 0.0007 & 0.0011 \\
\hline Li Jiaqi & 0.0017 & 0.4725 & 0.2292 & 0.0664 & 0.0017 & 0.0071 & 0.0108 \\
\hline Live streaming & 0.0331 & 0.2292 & 0.9999 & 0.2127 & 0.0889 & 0.1551 & 0.2059 \\
\hline Official & 0.0006 & 0.0664 & 0.2127 & 0.2127 & 0.0006 & 0.0023 & 0.0035 \\
\hline $\begin{array}{c}\text { Local economic } \\
\text { development }\end{array}$ & 0.0017 & 0.0002 & 0.0889 & 0.0006 & 0.0007 & 0.0011 \\
\hline $\begin{array}{c}\text { Rural revitalization } \\
\text { Product quality }\end{array}$ & 0.0007 & 0.0071 & 0.1551 & 0.0023 & 0.3354 & 0.0046 & 0.0046 \\
\hline
\end{tabular}

Finally, the network diagram of keywords is drawn according to the obtained cooccurrence matrix, as shown in Figure 2.

As can be seen from Figure 2, there are two main concerns in consumers' comments: Firstly, there are many disadvantages in the live streaming industry, among which the most mentioned by the public is the quality of goods in the live streaming, and the public hopes that the relevant regulatory authorities can reasonably supervise the platform, merchants, and anchors, so as to safeguard the consumers' rights and interests. This also shows that there are moral hazards in the transaction process of both the platform and the anchor in the process of the live streaming. Once consumers find that there are illegal transactions, it will not only have a negative impact on the anchor, but also consumers will consider choosing other platforms to buy goods in the future. This interest correlation is also the interest game point between the anchor and the platform. At the same time, the government has the supervision responsibility for the platform and needs to bear the supervision cost, which also affects the government's interests. Secondly, the recognition of the huge economic benefits brought by live streaming, especially the arrival of the epidemic, has made a large number of unsalable agricultural products in some areas with arduous task of poverty alleviation. Through live streaming, the sales channels have been widened and 
the unsalable problem of agricultural products has been better solved. The government strongly supports people to use the live streaming platform to sell their products, and the government and the live broadcast platform are the main key to promote the governance of live streaming. Both hope that the development of live delivery will bring benefits to themselves. However, the platform hopes that the government will give policy guarantee and reduce expenditure, while the government needs to reduce the governance cost. Therefore, the "who will come out" of the cost of the early live streaming management has become a point of conflict of interest between the two.

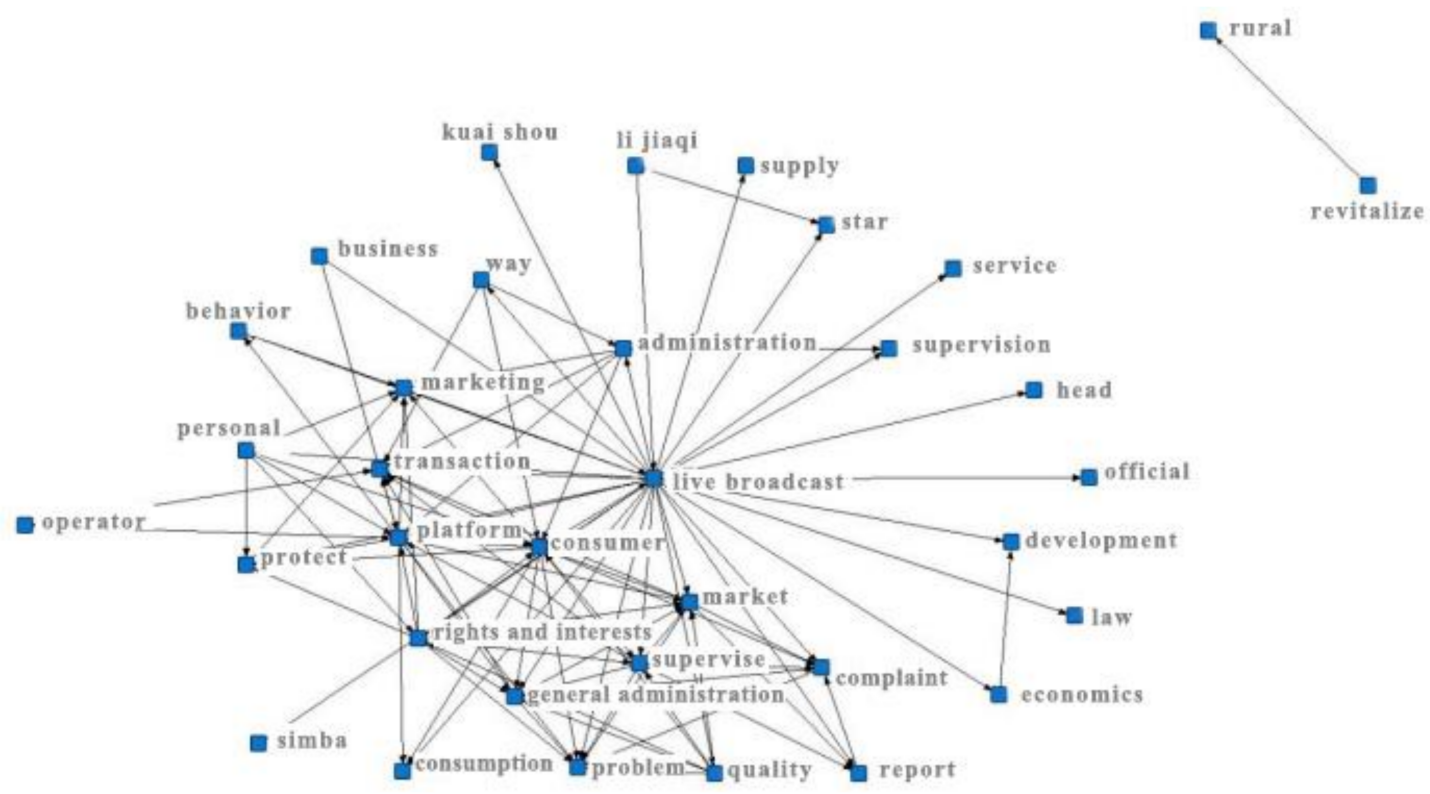

Figure 2. Co-occurrence matrix network diagram of keywords.

\subsubsection{Live Streaming Keywords Clustering}

Clustering the high-frequency topic words with rich information can identify the closely related topic word set in the co-occurrence network, so as to classify the topics discussed by the netizens and get the main topic categories of the people for the live streaming. In this paper, gCLUTO is used for two-way cluster analysis. The clustering method adopts the repeated dichotomy method and uses the cosine function to calculate the similarity. Isim, Isdev, Esim, Esdev, and Mountain map effect are used to adjust clustering effects [29]. The results are shown as below.

Figure 3 describes the situation and relationship of groups from a three-dimensional perspective, in which the height of peaks is directly proportional to the similarity in the category, the volume is directly proportional to the number of keywords contained in the category, the height between peaks indicates the similarity in the category, the color at the top of peaks reflects the standard deviation in the category (the red and blue colors indicate low standard deviation and high standard deviation, respectively), and the number at the top of peaks indicates the group. According to the mountain map, we can roughly know that the classification number of all subject words is 4 , and analyze the clustering results through the keywords in various groups, as shown in Figure 4. 


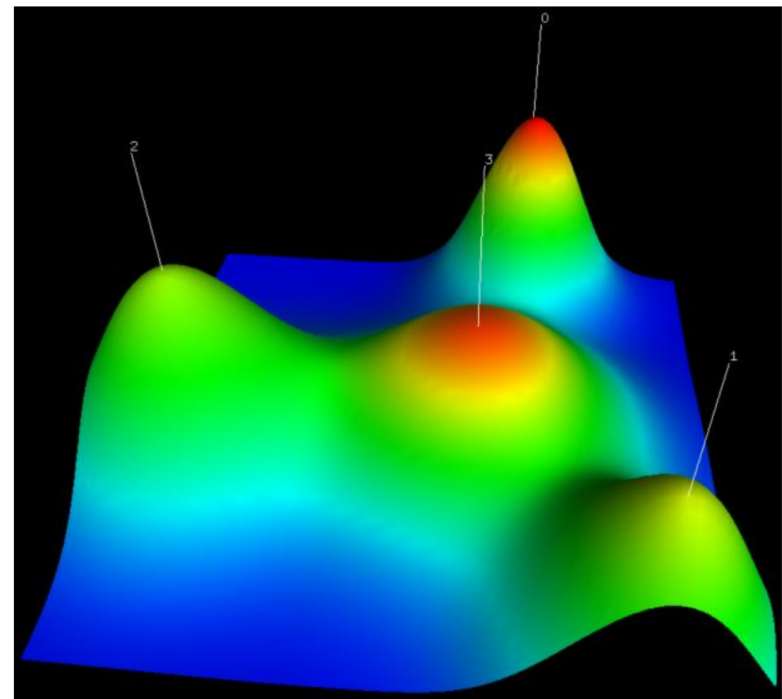

Figure 3. Mountain map.

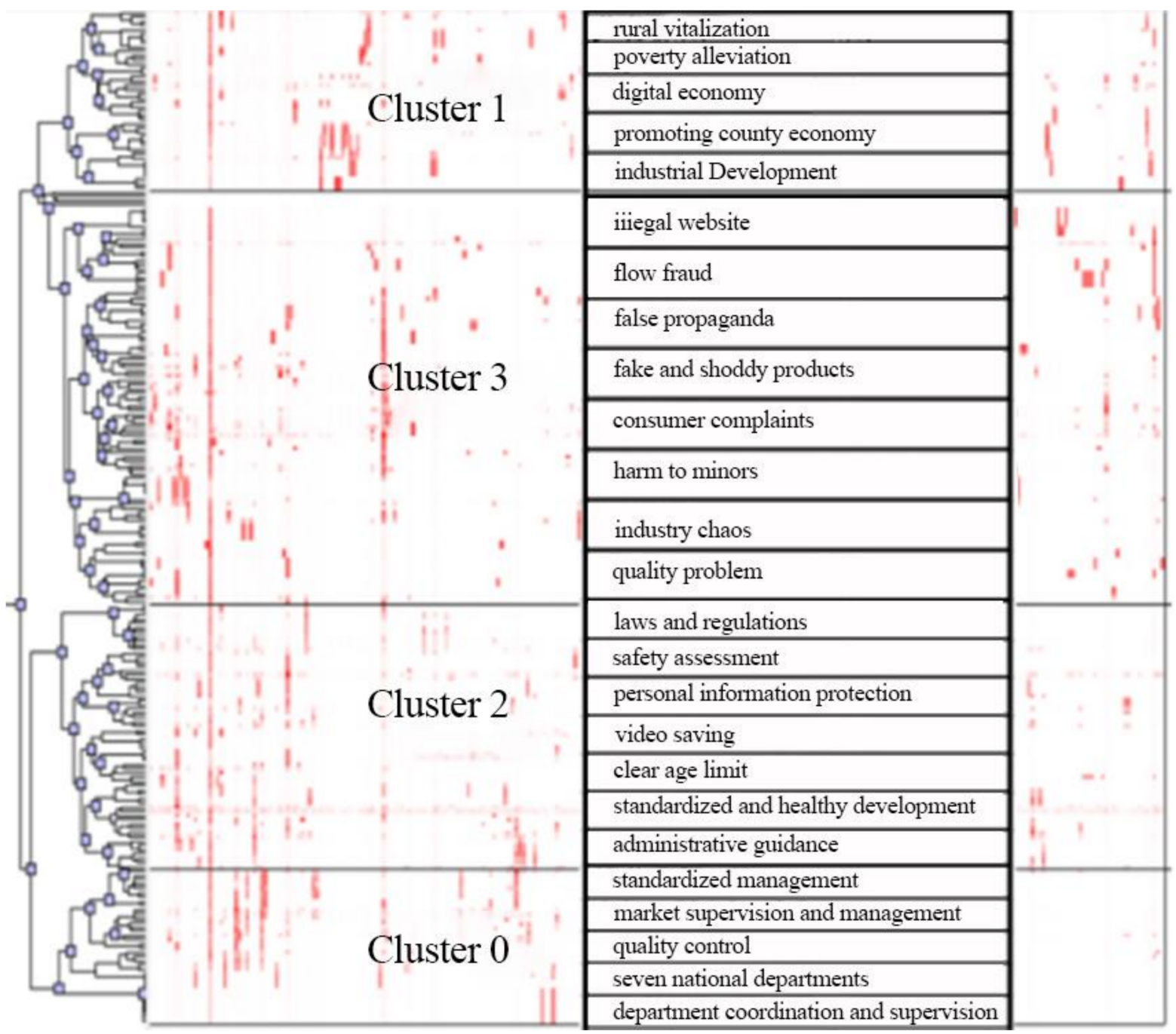

Figure 4. Clustering results of live streaming topics.

According to the clustering result in Figure 4, each category of keywords is summarized, in which cluster 1 is named "positive effect of live streaming", cluster 3 is named 
"negative effect of live streaming", cluster 0 is named "supervision of live streaming", and cluster 2 is named "regulation of live streaming".

According to the analysis of Internet topics related to live streaming in Sections 4.1.1-4.1.3 above, netizens' concerns about live streaming mainly focus on two parts: (1) How to improve the chaos of the existing live streaming industry, because the most prominent problems are fake and shoddy products, and there are no clear laws and regulations on direct streaming; (2) how to use live streaming to bring goods to promote economic development, especially rural industrial economy. Based on this, the follow-up will focus on the contents of the above live streaming environmental governance, and apply the obtained status to the evolutionary game process in the following, so as to build the game relationship among the subjects.

\subsection{Extraction of Subjects Based on Live Streaming Topic}

According to the above topic classification of live online commentary content, different subjects are involved in the live streaming, such as the brands, the government supervision department, the anchor of live streaming, etc. In order to safeguard their own best interests, there will be an interest game between the subjects. In the management of live streaming goods, each type of subjects needs to bear their own corresponding responsibilities. However, because the behavior decisions of different subjects will change according to their own interests, it is necessary to analyze the behavior decisions between different subjects. Before game analysis, we need to extract the key subjects according to the existing public comment information and discussion topics. In the past, most of the literatures directly obtained the main body of live streaming based on stakeholder theoretical analysis, and did not consider its related main body from the perspective of consumers. However, live streaming is a consumer-centered sales model. Based on this, the governance of live streaming environment should focus on the problems mentioned by consumers and explore the strategic choice among relevant subjects centered on consumers. Therefore, based on consumers' online comments, NLPIR is used to extract the entities of the four clustered keywords obtained in Section 4.1, and the subjects mentioned more in the four categories of topics are obtained. The results are shown in Table 5.

Table 5. Extraction of main subjects in live streaming.

\begin{tabular}{ccc}
\hline No & Stakeholder & Relevant words \\
\hline 1 & Anchors & Xinba, Dong Mingzhu, Luo Yonghao, Weiya, Li Jiaqi \\
\hline 2 & $\begin{array}{c}\text { Government } \\
\text { departments }\end{array}$ & $\begin{array}{r}\text { General Administration of market supervision, market supervision } \\
\text { department, market supervision and administration department, } \\
\text { coordination and supervision department, public security organ } \\
\text { and seven national departments }\end{array}$ \\
\hline 3 & Brands & $\begin{array}{r}\text { Mengiie, RED DRAGONFLY, GREE, alcohol merchants, Beijing } \\
\text { Office Education \& Technology Co., Ltd., education institution }\end{array}$ \\
\hline 5 & Platforms & Taobao, Douyin, Kuaishou, Anchor platform, JD \\
\hline
\end{tabular}

It can be seen from Table 5 that among the topics that netizens pay more attention to, they mainly mention the front-tier anchors (influential opinion leaders), government regulatory departments, brand (businesses), live streaming platforms, and consumers. Among them, the brand will hire front-tier anchors to sell products. If there is a problem with the merchant's products in the live streaming, the anchors will also bear the corresponding responsibility. Therefore, in the later discussion on the collaborative governance of multiple subjects of live streaming, the anchor is regarded as the product representative of the brand, and only four types of subjects are considered: government, live streaming platform, consumers and anchors. In addition, it can be seen from the anchor mentioned in Table 5 above that most of the sales of the existing live streaming industry come from 
fixed anchors, such as Li Jiaqi, Weiya. Therefore, in the environmental governance of the live streaming industry, we should focus on such front-tier anchors and make use of the influence of anchors to do more social public welfare activities. At the same time, for the chaos in the industry, we can also start supervision from such front-tier anchors to set a good example for social governance.

\section{Game Analysis of Cooperative Governance of Multiple Subjects in Live Streaming Based on Social Preference Theory}

The environmental governance of live streaming is a systematic project. Combined with the contents of Section 4.2, the process involves four main subjects, which requires the government, live streaming platform, consumers and anchors to clarify their respective tasks and division of labor. Based on the stakeholder theory, the existing research discusses the internal mechanism of environmental governance of live streaming under the participation of multiple parties through game evolution, and is based on the premise and assumption of traditional economics: individuals have rational egoism preferences, and seek the optimization results in the face of environmental constraints [30]. However, individual preferences include both egoism preferences and altruistic preferences [31], which include altruistic behavior into individual utility function, so as to expand individual "egoism preferences" and make other people's utility (Welfare) become a new source of individual utility [32]. Therefore, individual behavior preference has not only egoism, but also altruism. Behavioral economists call individual altruism as "prosocial" and prosocial preferences as "social preferences" [33].

Rabin [34] was recognized as the first "mutual benefit" model based on motivation fairness, which creatively formalized the social preference theory. The famous behavioral economist Camerer [35] put forward the concept of "social preference" completely for the first time. Ortona [36] summarized and analyzed the theory of social preference and pointed out that social preference meant that decision-makers would care about the benefits of others while paying attention to their own benefits, mainly including altruistic preference, fair preference and reciprocal preference. Mercy and justice are indispensable components of human nature, and they are lubricants for the good operation and continuous progress of the whole human society. However, this basic understanding of human nature has been excluded from the broker hypothesis in economics. Due to the limitations and narrowness of the broker self-interest model in traditional economics, a large number of prosocial behaviors found in experimental economics, especially in individual behavior game experiments, cannot be explained by mainstream economic theories [37]. Therefore, this paper introduced the theory of social preference to discuss the game process of individual behavior, so that the game process is closer to individual social behavior. The social preference theory in this paper was mainly applied to the influence of individual utility function. Social preference can be roughly divided into three kinds of preferences, namely altruistic preference, difference aversion preference, and reciprocal preference, which correspond to people's kindness, fairness, and mutual assistance. Altruistic preference refers to the positive correlation between the interests of others and their own utility in people's utility function. According to the reciprocal preference based on psychological motivation, people will reward good for good and punish evil for evil, even though they need to pay a certain cost. According to the resultbased difference aversion preference, people will have utility loss when they are unfair in disadvantages and unfair in advantages, and the loss of unfair in disadvantages is greater than that of unfair in advantages.

According to the research on the literature of social preference measurement, Ashley et al. [38] gave the measurement method of testing social preference in the experimental environment of public goods for the first time, while Andreoni and Miller [39] showed that altruistic preference was rational for both individuals and the whole society, and altruistic behavior could be studied and quantified by relevant models of economics, so as to measure altruistic preference $[40,41]$. The method of social questionnaire could be used to measure reciprocity preference [42], in which the GSS (General Social Survey) social 
questionnaire was a common method. When designing the content of GSS questionnaire, three variables of trust, fairness, and helping others were selected to construct a comprehensive standardized trust index called GSS trust index. The obtained data were analyzed quantitatively, so that the degree of reciprocity preference could be measured scientifically and truly.

Based on this, this paper integrated the social preference theory to discuss the game process of multi-agent collaborative governance [43]. At the same time, according to the nature of the main body, the process of the environmental governance of live streaming is divided into two stages: First, the governance promotion stage with the "government" as the key node, and the government can restrict the behavior of other subjects by formulating rules and regulations. The second is the transaction stage between the buyer and the seller with "consumers" as the key node. By restricting the behavior of the main body in the transaction process, it can control the bad environment of live streaming, and the promotion stage of government governance provides corresponding conditions and environment for the good transaction of live streaming.

\subsection{Promotion Stage: The Evolutionary Game Process between Government and Live Streaming Platform}

It can be seen from Section 4.1.2 that consumers want the relevant regulatory authorities to reasonably supervise the live streaming merchants and anchors, i.e., to create a good live streaming environment, and the government departments and live streaming platforms are the main stakeholders in promoting the governance of live streaming. As a strong governance subject, the government's governance is reasonable and legitimate. The platform holds the technical advantages and controls over anchors. While obtaining benefits, it also needs to bear the responsibility of governance, and make full use of the external power of the platform to assist the government in supervising the bad behavior during live streaming. In the process of participating in the governance of live streaming, government departments and live streaming platforms not only have consistent interests, but also some conflicts of interest. First of all, the development of live streaming can bring certain benefit increment to both. Both hope to participate in the development of live streaming and promote their good development. Therefore, from the perspective of willingness to participate, the basic demands of the government and the live streaming platform are the same. However, from the perspective of participation methods and objectives, government departments hope to promote the progress of the whole industry by guiding the sound development of live streaming. At the same time, government departments need to reduce the cost of participating in the management of live streaming and reduce unnecessary financial expenditure; the live streaming platform hopes that the government departments will give more policy and infrastructure guarantee, reduce the cost of participating in governance and improve the gain. Therefore, the cost of governing live streaming has become a conflict of interest between government departments and live streaming platforms. The following analyzes the behavior decision game process between the government and the platform.

Per the functionality of the government, if the live streaming platform has nonstandard behavior, the government can give corresponding punishment, while the platform with good social impact can be given corresponding rewards, i.e., the government has reciprocal preference and altruistic preference for the platform. At the same time, if the live streaming platform wants to operate for a long time, it must do a good job in standardizing the anchor behavior and protecting the interests of consumers; in other words, the platform has altruistic preference. The government and the platform can change their preferences through specific measures and develop in the direction conducive to the governance of live streaming environment. Table 6 displays the corresponding measures. Here, we can learn from the C\&R model obtained by Charles et al. [44,45] and Fehr [46] by incorporating 
multiple preferences into a unified analysis framework. Taking the utility $U B$ of participant $B$ as an example, the model is expressed as:

$$
U_{\mathrm{B}}\left(\pi_{\mathrm{A}}, \pi_{\mathrm{B}}\right)=\pi_{\mathrm{B}}+(\rho+\theta q)\left(\pi_{\mathrm{A}}-\pi_{\mathrm{B}}\right), q=\left\{\begin{array}{c}
-1, \text { if Aisunfriendly } \\
0, \text { if Aisfriendly }
\end{array}\right.
$$

where $\theta$ is reciprocal preference parameter, $\rho$ is altruistic preference parameter.

Table 6. The government-platform governance measures in the promotion stage.

\begin{tabular}{|c|c|c|}
\hline Subject & Specific Measures & Results \\
\hline \multirow{4}{*}{ Government } & $\begin{array}{c}\text { Lower the admission qualification requirements or reduce the amount of fines } \\
\text { for enterprises engaged in convenient labor services and rural revitalization } \\
\text { through the Internet, and use "warning", "education", and "reminder" instead } \\
\text { of tough criminal means. }\end{array}$ & $\begin{array}{l}\text { Weakening the government's } \\
\text { reciprocal preference }\end{array}$ \\
\hline & $\begin{array}{l}\text { The supervision administration department may increase the amount of fines for } \\
\text { enterprises that commit illegal acts on the live streaming platform and fail to } \\
\text { correct within the time limit. If the platform fails to fulfill its obligation to review } \\
\text { the qualifications of operators in the platform or its sales services infringe upon } \\
\text { the legitimate rights and interests of consumers, increase the civil joint and } \\
\text { several liability that the platform needs to bear; specify and expand the scope of } \\
\text { bad behaviors in the platform that need to bear corresponding legal liabilities; } \\
\text { publicize the information of enterprises with past administrative penalties, } \\
\text { abnormal operation list and serious violations and dishonesty, and improve the } \\
\text { operation benchmark requirements for such enterprises or monitor the operation } \\
\text { of enterprises in real time. }\end{array}$ & $\begin{array}{l}\text { Strengthening the } \\
\text { government's reciprocal } \\
\text { preference }\end{array}$ \\
\hline & $\begin{array}{l}\text { To reduce the supervision cost and financial expenditure, it can reduce the } \\
\text { reward, subsidy, and loan amount to the platform for enterprises with bad } \\
\text { behavior, and increase the tax amount to enterprises. }\end{array}$ & $\begin{array}{l}\text { Weakening the government's } \\
\text { altruistic preference }\end{array}$ \\
\hline & $\begin{array}{l}\text { Increase the entry incentives for the platform (start-up incentives and office } \\
\text { space subsidies according to the years of settlement and the comprehensive } \\
\text { contribution of enterprises to regional economic and social development), listing } \\
\text { incentives (incentives for live e-commerce enterprises newly listed on } \\
\text { Main-Board Market and The Science and Technology Innovation Board), } \\
\text { financial incentives (enabling enterprises to obtain green loans by means of } \\
\text { commercial loans; in addition, enterprises are encouraged to purchase insurance } \\
\text { and give subsidies), income generating rewards (rewards will be given } \\
\text { according to the contribution of the part of enterprises carrying goods to local } \\
\text { economic development), honor rewards (rewards will be given to the national, } \\
\text { provincial, and municipal e-commerce demonstration enterprises and MCN } \\
\text { institutions officially certified by major e-commerce platforms according to their } \\
\text { contribution to regional economic development). Subsidize the cost of holding } \\
\text { live streaming activities (encourage enterprises to hold live streaming } \\
\text { e-commerce activities with industry influence), and coordinate logistics } \\
\text { enterprises in the region to support key live streaming e-commerce. }\end{array}$ & $\begin{array}{l}\text { Strengthening the } \\
\text { government's altruistic } \\
\text { preference }\end{array}$ \\
\hline
\end{tabular}

Lower the qualification review of operators who settled in. Raise the cost standard for operating the platform. Respond to the government in time for bad behaviors on the platform.
Weakening the government's altruistic preference
Live streaming platforms should consciously improve information audit and information security management, dynamically monitor market operators, and report to relevant government departments for violations of market supervision laws and regulations. The qualification requirements of the operators entering the platform should be raised, verified, and registered, and the verification and renewal should be carried out periodically. The platform actively participates in public welfare live streaming activities held by government departments, and provides free sales platform or technical support for rural revitalization.

Popularize the government's supervision and management laws and regulations to the operators in the platform, and improve the operators' awareness of standardized behavior.

Strengthening the platform's altruistic preference 
According to formula (5), the game parameters between the government and the platform are set. The government's strategy set is (supervision, non-supervision), and the strategy set of the live streaming platform is (standardized operation, non-standardized operation), the specific game process is shown in Figure 5.

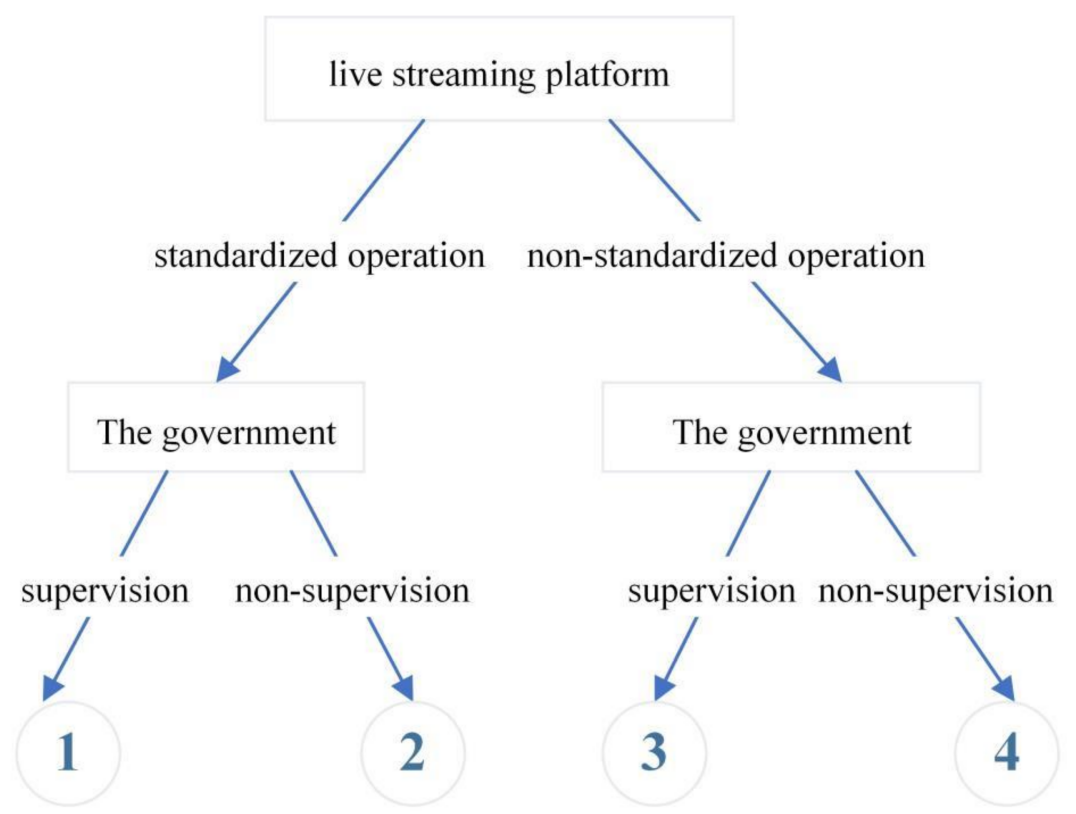

Figure 5. Game tree of "live streaming platform-the government".

In the game process of "government live streaming platform", the relevant parameter definitions and the income risk matrix involved in the income risk matrix of the two entities are shown in Tables 7 and 8.

Table 7. The definition of parameters involved in the game between the government and the live streaming platform.

\begin{tabular}{cc}
\hline Parameters & Definition \\
\hline$C_{1}$ & The cost of government supervision \\
\hline$P_{1}$ & $\begin{array}{r}\text { Profits from supervision implemented by government departments (promoting social } \\
\text { and economic development and improving government departments' credibility) }\end{array}$ \\
\hline$S_{1}$ & $\begin{array}{r}\text { Loss of government departments when the live streaming platform with } \\
\text { non-standardized operation (for example, loss of government credibility, loss of } \\
\text { reputation by public opinion) }\end{array}$ \\
\hline$P_{4}$ & Profits when the government does not supervise but the platform operates in a \\
standardized manner
\end{tabular}


Table 7. Cont.

\begin{tabular}{|c|c|}
\hline Parameters & Definition \\
\hline$\delta_{2}$ & $\begin{array}{l}\text { The degree of altruistic preference of the online live streaming platform } \\
\text { (value range }[0,1] \text { ) }\end{array}$ \\
\hline$x$ & Probability of government supervision (value range $[0,1]$ ) \\
\hline$y$ & $\begin{array}{l}\text { Probability of online live streaming platform with standardized operation } \\
\text { (value range }[0,1] \text { ) }\end{array}$ \\
\hline
\end{tabular}

Table 8. The return and risk matrix of government and online live streaming platform.

\begin{tabular}{|c|c|c|c|}
\hline \multicolumn{4}{|c|}{ Government } \\
\hline & & Supervision & Non-Supervision \\
\hline \multirow{2}{*}{$\begin{array}{l}\text { Live streaming } \\
\text { platform }\end{array}$} & $\begin{array}{l}\text { standardized } \\
\text { operation }\end{array}$ & $\begin{array}{l}\left(\left(P_{2}-C_{2}\right)+\delta_{2}\left(P_{1}-C_{1}-P_{2}+C_{2}\right)\right. \\
\left.\left(P_{1}-C_{1}\right)+\delta_{1}\left(P_{2}-C_{2}-P_{1}+C_{1}\right)\right)\end{array}$ & $\begin{array}{c}\left(P_{2}-C_{2}+\delta_{2}\left(P_{4}-P_{2}+C_{2}\right)\right. \\
\left.P_{4}+\delta_{1}\left(P_{2}-C_{2}-P_{4}\right)\right)\end{array}$ \\
\hline & $\begin{array}{l}\text { Non-standardized } \\
\text { operation }\end{array}$ & $\begin{aligned} & \left(P_{3}-S_{2}+\delta_{2}\left(P_{1}-C_{1}-S_{1}-P_{3}+S_{2}\right)\right. \\
P_{1}- & \left.C_{1}-S_{1}+\left(\delta_{1}-\theta\right)\left(P_{3}-S_{2}-P_{1}+C_{1}+S_{1}\right)\right)\end{aligned}$ & $\begin{array}{c}\left(P_{3}+\delta_{2}\left(-S_{1}-P_{3}\right)\right. \\
\left.-S_{1}+\left(\delta_{1}-\theta\right)\left(P_{3}+S_{1}\right)\right)\end{array}$ \\
\hline
\end{tabular}

\subsubsection{Equilibrium Analysis of Evolutionary Games}

According to Table 8, the dynamic replication equation of the government and the live streaming platform is obtained.

The government's dynamic replication equation is:

$$
\mathrm{F}(x)=\frac{d x}{d t}=x(1-x)(\mathrm{M} *+y \mathrm{~N} *)
$$

where $\mathrm{M}^{*}=P_{1}-C_{1}-\delta_{1}\left(S_{2}+P_{1}-C_{1}\right)+\theta\left(S_{2}+P_{1}-C_{1}\right), \mathrm{N}^{*}=\delta_{1}\left(S_{2}+P_{4}\right)-\theta\left(S_{2}+P_{1}-\right.$ $\left.C_{1}\right)-P_{4}$.

The live streaming platform's dynamic replication equation is:

$$
\mathrm{F}(y)=\frac{d y}{d t}=y(1-\mathrm{y})(\mathrm{Q} *+x \mathrm{~V} *)
$$

where $\mathrm{Q}^{*}=P_{2}-C_{2}-P_{3}+\delta_{2}\left(P_{4}-P_{2}+C_{2}+S_{1}+P_{3}\right), \mathrm{V}^{*}=S_{2}-\delta_{2}\left(P_{4}+S_{2}\right)$. If $\mathrm{F}(x)=0$, $\mathrm{F}(y)=0$. The five local equilibrium points of the system can be obtained, which are $(0,0)$, $(0,1),(1,0),(1,1),\left(-\frac{Q *}{V *},-\frac{M *}{N *}\right)$, respectively. According to Jacobian matrix local equilibrium point stability analysis method proposed by Friedman [47], local stability analysis was performed, and the Det $J$ and TrJ values of five local equilibrium points were obtained. The Jacobian Matrix of the system is:

$$
J=\left[\begin{array}{ll}
\frac{\partial F(x)}{\partial x} & \frac{\partial F(x)}{\partial y} \\
\frac{\partial F(y)}{\partial x} & \frac{\partial F(y)}{\partial y}
\end{array}\right]=\left[\begin{array}{cc}
(1-2 x)(M *+y N *) & x(1-x) N * \\
y(1-y) V * & (1-2 y)(Q *+x V *)
\end{array}\right]
$$

If $\operatorname{Det} J<0$, then the equilibrium point is in a local stable state, which indicates that the strategy cannot make the public opinion reach an evolutionary stable state. If Det $>0$ and $\operatorname{TrJ}$ sign is uncertain, the equilibrium point is in a local stable state. If $\operatorname{Det} J>0$ and $\operatorname{Tr} J<0$, it indicates that the government and platform are in equilibrium and in an evolutionary stable state. According to the above definition, through solution and stability judgment analysis, the stability conditions of each decision combination are obtained as shown in Table 9 below. 
Table 9. Equilibrium point and the value of DetJ and TrJ.

\begin{tabular}{|c|c|c|c|c|c|}
\hline $\begin{array}{l}\text { Equilibrium } \\
\text { Point }\end{array}$ & $\begin{array}{l}\text { Symbol of } \\
\text { TrJ }\end{array}$ & $\begin{array}{c}\text { Symbol of } \\
\text { DetJ }\end{array}$ & Equilibrium Condition & Result & $\begin{array}{l}\text { Equilibrium } \\
\text { Strategy }\end{array}$ \\
\hline$(0,0)$ & + & + & - & Saddle point & - \\
\hline$(0,1)$ & + & - & - & Saddle point & - \\
\hline$(1,0)$ & - & + & $\begin{array}{c}S_{1}+P_{3}-S_{2}<P_{2}-C_{2} \\
\delta_{1}-\frac{P_{1}-C_{1}-\left(P_{2}-C_{2}\right)-P_{3}-S_{2}}{S_{2}+P_{1}-C_{1}}<\theta<\delta_{1} \\
\frac{P_{1}-C_{1}-\left(P_{2}-C_{2}\right)-P_{3}-S_{2}-\left(\delta_{1}-\theta\right)\left(S_{2}+P_{1}-C_{1}\right)}{S_{1}+P_{3}-P_{2}+C_{2}-S_{2}}<\delta_{2} \\
\delta_{2}<-\frac{\left(P_{2}-C_{2}+P_{3}+S_{2}\right)}{S_{1}+P_{3}-P_{2}+C_{2}-S_{2}}\end{array}$ & $\mathrm{ESS}_{1}$ & $\begin{array}{c}\text { (supervision, } \\
\text { non-standardized } \\
\text { operation) }\end{array}$ \\
\hline$(1,1)$ & - & + & $\left\{\begin{array}{c}S_{1}+P_{3}-S_{2}<P_{2}-C_{2} \\
0<\delta_{2}<-\frac{P_{2}-C_{2}+P_{3}+S_{2}}{S_{1}+P_{3}-P_{2}+C_{2}-S_{2}}\end{array}\right.$ & $\mathrm{ESS}_{2}$ & $\begin{array}{l}\text { (supervision, } \\
\text { standardized } \\
\text { operation) }\end{array}$ \\
\hline $\begin{array}{l}\left(-\frac{Q *}{V *}\right. \\
\left.-\frac{M *}{N *}\right) \\
\end{array}$ & 0 & 0 & - & Saddle point & - \\
\hline
\end{tabular}

It can be seen from Table 9 that only when $(1,0)$ and $(1,1)$ meet the equilibrium conditions in the above table, they can become equilibrium points ESS 1 and $\mathrm{ESS}_{2}$, so as to achieve equilibrium state. Next, through simulation analysis, we discuss the impact of different subjects' preferences on the evolutionary equilibrium strategy when the two types of equilibrium points are evolutionary stability points. Firstly, the above game model was discretized, and the discrete mathematical expression of the behavior strategy choice of two participants was obtained, as shown in equation 9:

$$
\left\{\begin{array}{l}
\frac{d x}{d t}=\frac{x(t+\Delta t)-x(t)}{\Delta t}=x(1-x)(M *+y N *) \\
\frac{d y}{d t}=\frac{y(t+\Delta t)-y(t)}{\Delta t}=y(1-y)(Q *+x V *)
\end{array}\right.
$$

\subsubsection{Discussion and Numerical Simulation of Evolutionary Game Results}

In order to explore the influences of altruistic preference and reciprocal preference on the strategy evolution direction and evolution speed of the government and live streaming platform in the governance of live streaming environment, the evolutionary equilibrium strategy points $(1,0),(1,1)$ were taken as examples for simulation analysis.

Simulation Analysis of Evolutionary Equilibrium Strategy Points $(1,0)$

Combined with the actual situation of live streaming and literatures [36-38,44], each parameter assignment is as follows: $C_{1}=1.5, P_{1}=6, S_{1}=1, P_{4}=2.5, P_{2}=5.5, P_{3}=6, S_{2}=1.5$, $C_{2}=2$, the initial value of $(x, y)$ is $(0.5,0.5)$. According to Table 8 , the preconditions need to be met: $0 \leq \theta<\delta_{1} \leq 1,0 \leq \delta_{2} \leq 1$ (in the following analysis, the subject's preference value close to 1 indicates to strengthen preference, and its preference value close to 0 indicates to weaken preference). Among them, there may be two situations for the live streaming platform: (1) when $\delta_{2}=0$, i.e., when the live streaming platform's altruistic preference is close to 0 , i.e., the platform holds egoistic preferences (see Figures 5-8); (2) when $\delta_{2} \neq 0$, i.e., the platform holds altruistic preference (see Figures 9-18). The two situations will be discussed below.

(1) When platform holds altruistic preference, $\delta_{2}=0$

Figures 6 and 7 demonstrate that the government and the live streaming platform finally choose supervision and non-standardized operation as the evolutionary equilibrium strategy. At this time, the benefits of the platform's non-standardized operation are obviously greater than the benefits of the standardized operation. When the platform's altruistic preference approaches 0 , strengthening the government's altruistic preference will accelerate the evolution of the platform and the equilibrium strategy will approach irregular operations, and the speed of the government's supervision of platform violations 
will slow down. When the government's reciprocal preference increases, the government will participate more quickly in the environmental governance of live streaming, and it will be later for the network platform to tend to non-standardized operation strategies. In other words, appropriately strengthening the government's reciprocal preference and weakening the government's altruistic preference will help control the chaos of live streaming. The specific measures are presented in Table 6.

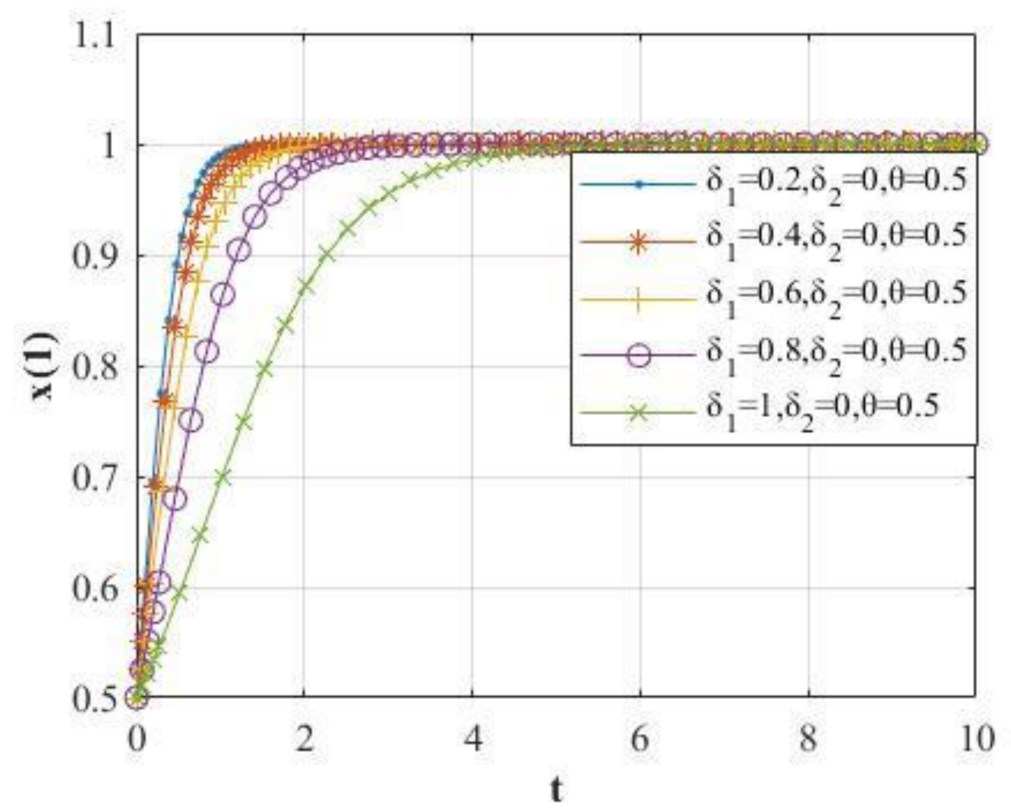

(a)

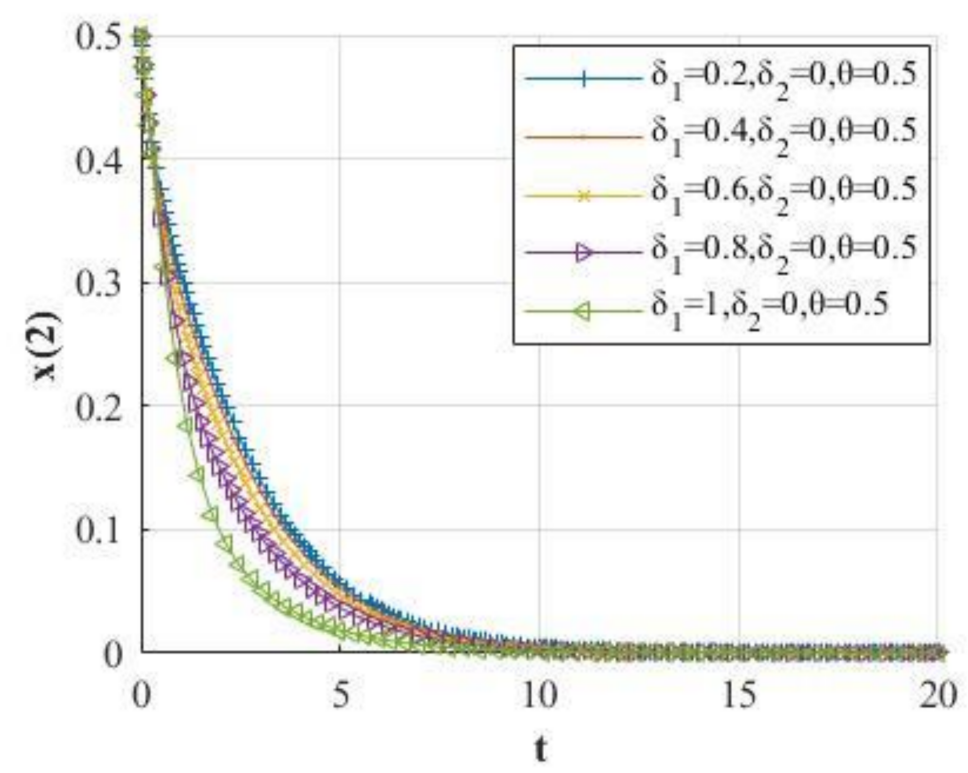

(b)

Figure 6. (a) While $\theta=0.5$ and changing $\delta_{1}$, evolution diagram of government's supervision option. (b) While $\theta=0.5$ and changing $\delta_{1}$, evolution diagram of platform's supervision option. 


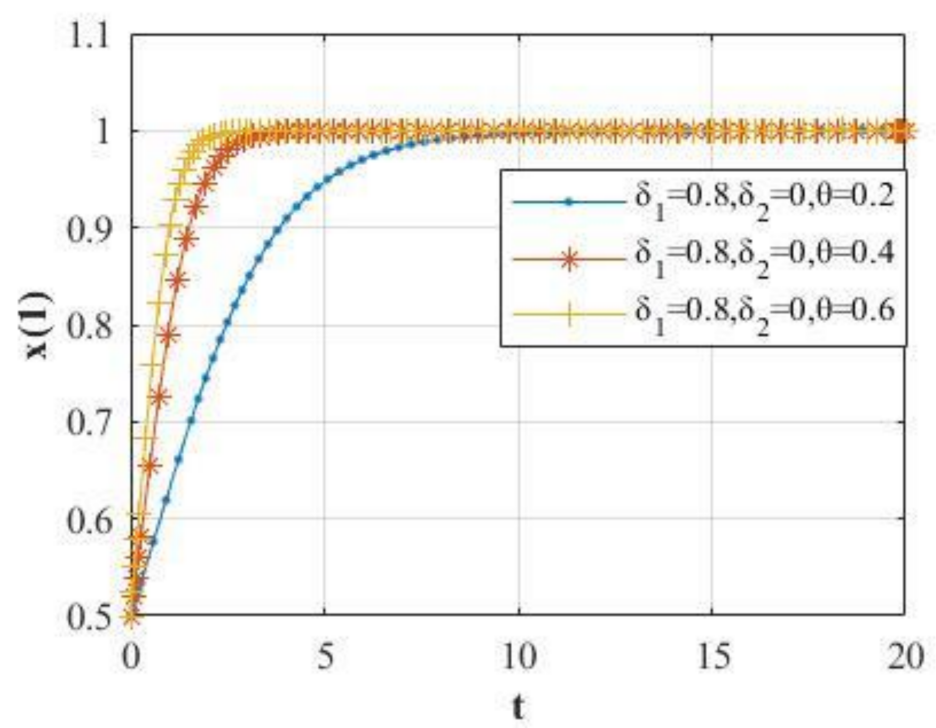

(a)

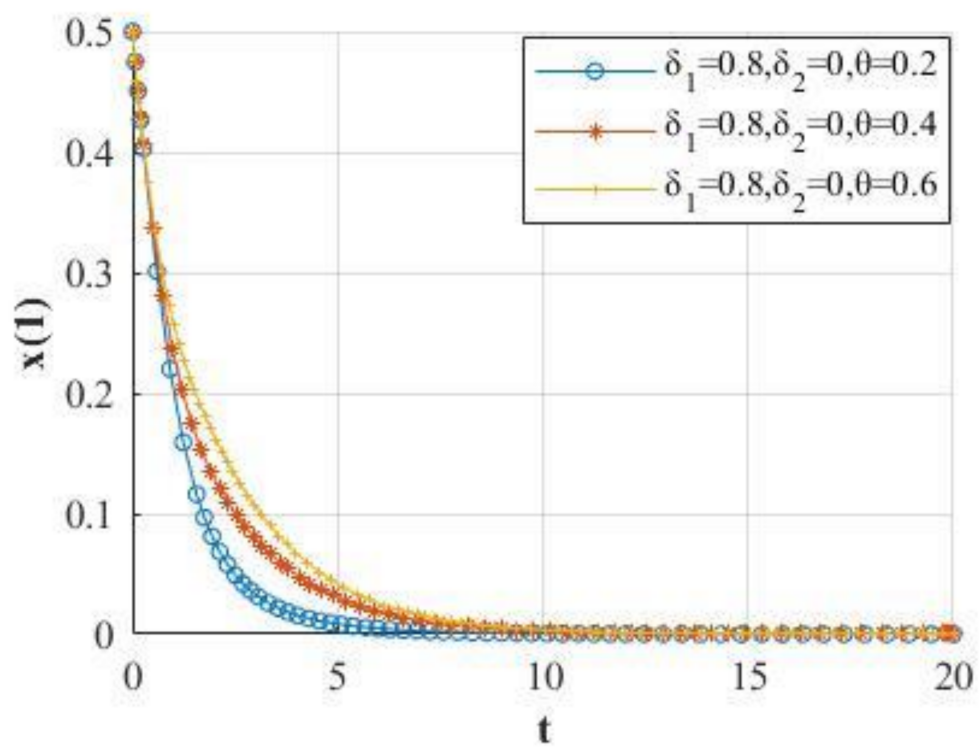

(b)

Figure 7. (a) While $\delta_{1}=0.8$ and changing $\theta$, evolution diagram of government's supervision option. (b) While $\delta_{1}=0.8$ and changing $\theta$, evolution diagram of platform's supervision option.

(2) When platform holds altruistic preferences, $\delta_{2} \neq 0$

Figures 8-10 demonstrate that when the online live streaming platform holds altruistic preferences, strengthening the government's reciprocal preference will not improve the illegal activities of the live streaming platform. It can only allow the government to participate in the governance of the live streaming earlier, and then increase the cost of government governance. If the government does not change its own reciprocal preference intensity at this time, then the platform will strengthen its own altruistic preference accordingly, and its behavior evolution strategy will change from the non-standardized operation to standardized operation.

Simulation Analysis of Evolutionary Equilibrium Strategy Point $(1,1)$

Combined with the actual situation of live streaming and literature [48], each parameter assignment is as follows: $C_{1}=1.5, P_{1}=6, S_{1}=1, P_{4}=2.5, P_{2}=5.5, P_{3}=4, S_{2}=1.5$, 
$C_{2}=1$. The initial value of $(x, y)$ is $(0.5,0.5)$. According to Table 9 , the preconditions need to be met at this time: $0 \leq \theta, \delta_{1}, \delta_{2} \leq 1$. Under this evolutionary equilibrium strategy, the platform strategy is standardized operation, i.e., the platform considers that a good live streaming environment is good for social and economic development, so the platform does not hold egoistic preferences. In the case of $\delta_{2} \neq 0$, the results are shown in Figures 11-13.

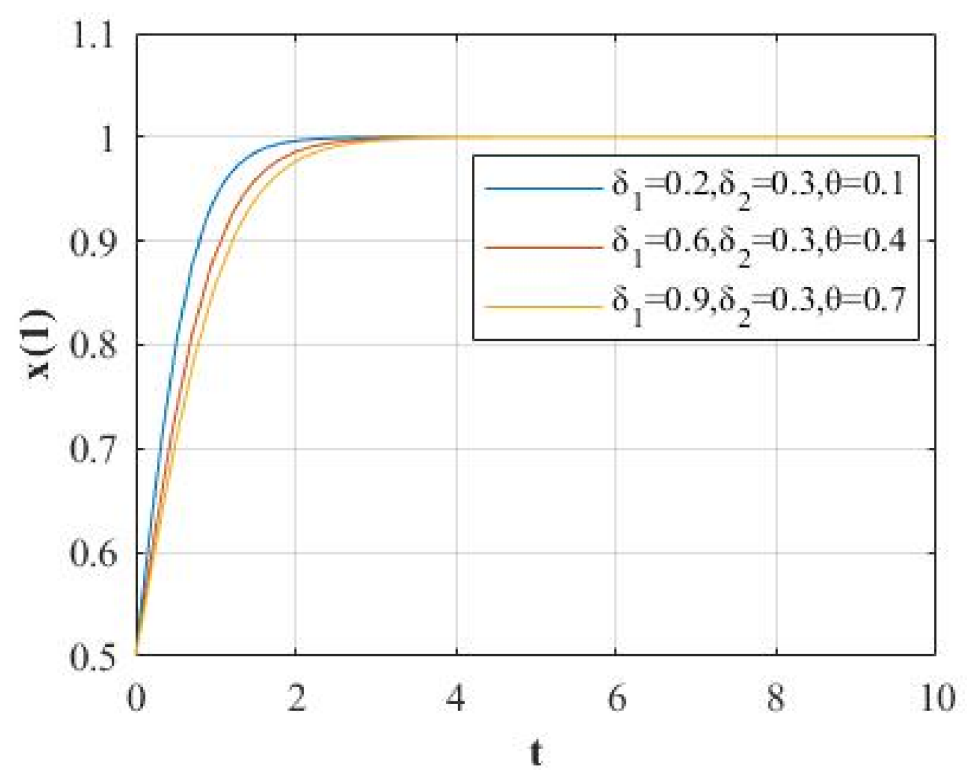

(a)

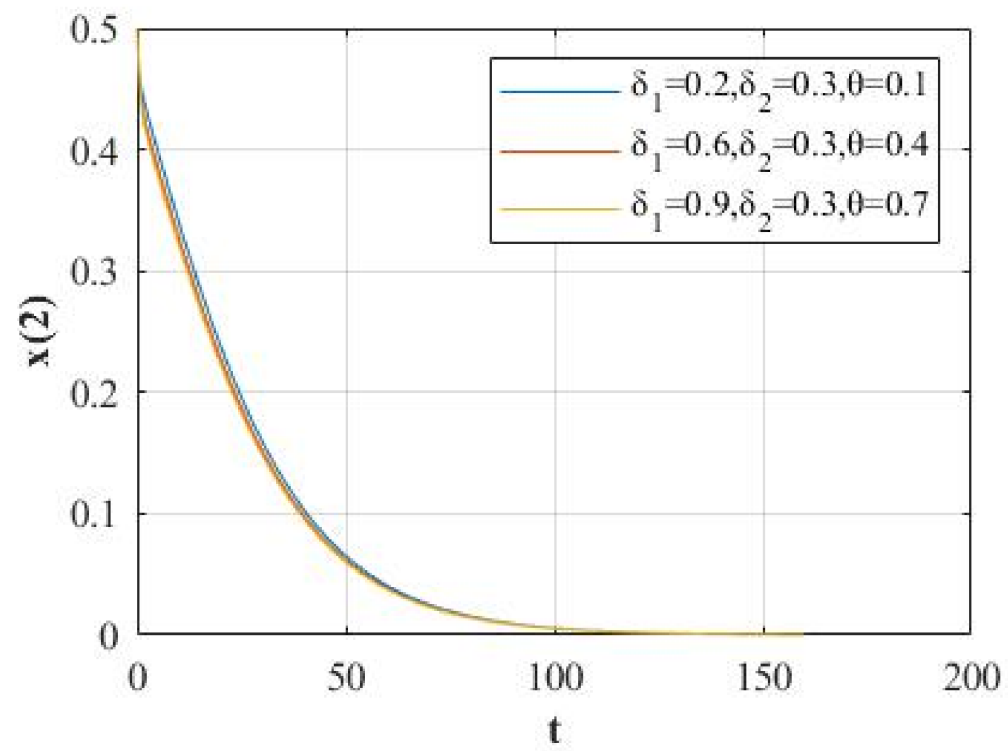

(b)

Figure 8. (a) While changing $\delta_{1}$ and $\theta$, and $\delta_{2}=0.3$, evolution diagram of government's supervision option. (b) While changing $\delta_{1}$ and $\theta$, and $\delta_{2}=0.3$, evolution diagram of platform's supervision option. 


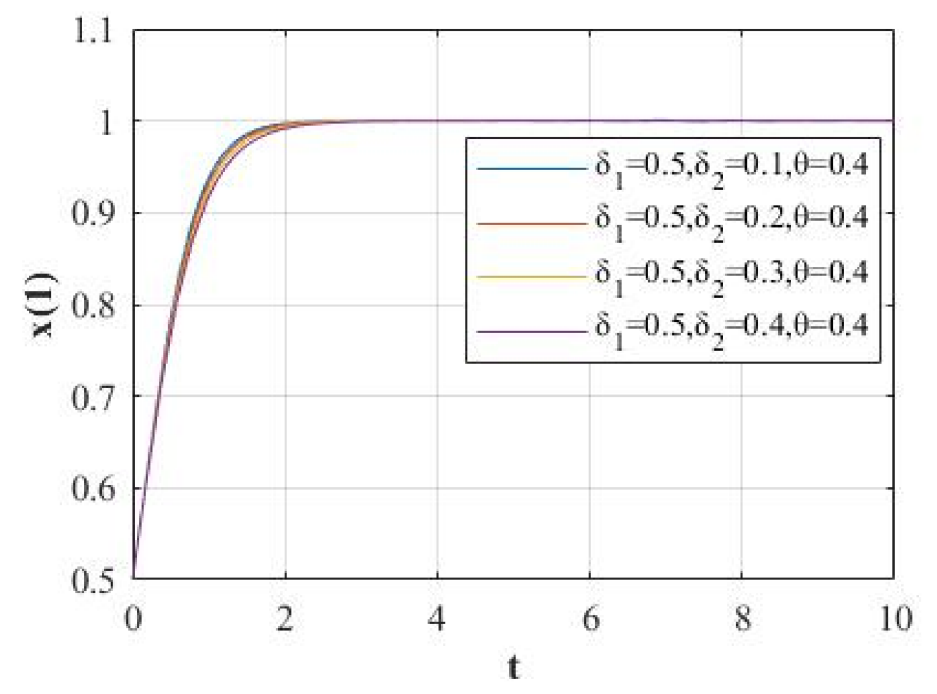

(a)

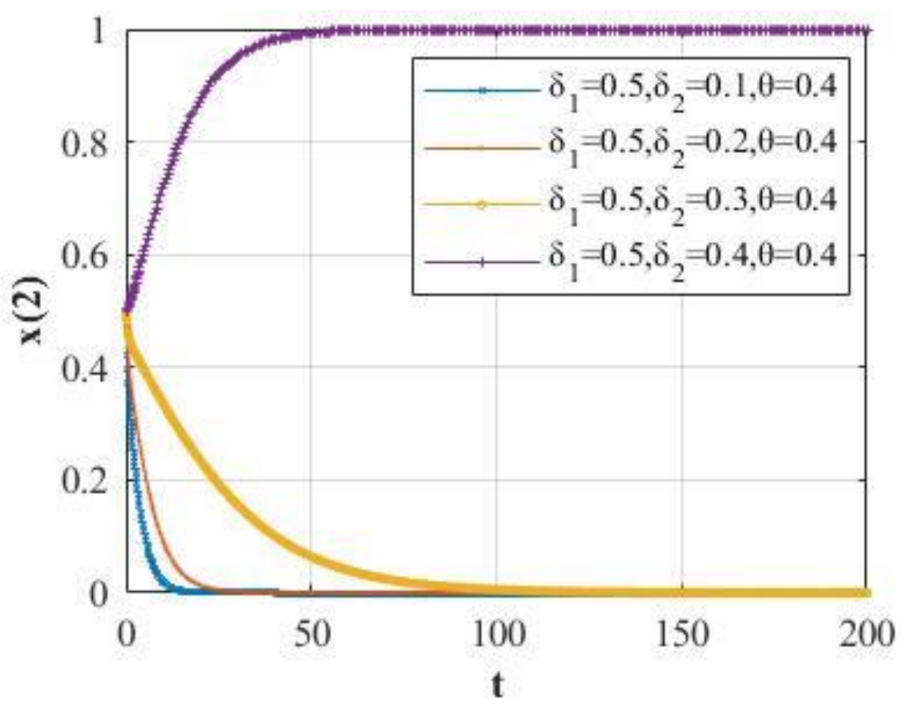

(b)

Figure 9. (a) While changing $\delta_{2}$ and $\delta_{1}=0.5, \theta=0.4$., evolution diagram of government's supervision option. (b) While changing $\delta_{2}$ and $\delta_{1}=0.5, \theta=0.4$., evolution diagram of platform's supervision option.

Figures 11-13 illustrate that the final evolutionary equilibrium strategy of the government and live streaming platform is (supervision, standardized operation). In this case, the government strengthens its own altruistic preference, and the platform correspondingly weakens its own altruistic preference. Meanwhile, it is conducive to accelerating the standardized operation of the platform; at the same time, the government does not have to participate in the governance of live streaming prematurely, which can reduce supervision costs. For example, when the epidemic prevention and control is normalized, in order to promote new consumption methods, the government encourages entity businesses to open new models such as "online shopping" through e-commerce live streaming and social marketing, and provides rental subsidies, financial support, and research and development subsidies to live streaming companies. Such measures can promote the standardized operation of the platform and strive to develop into a benchmark and demonstration enterprise in the live streaming industry. 


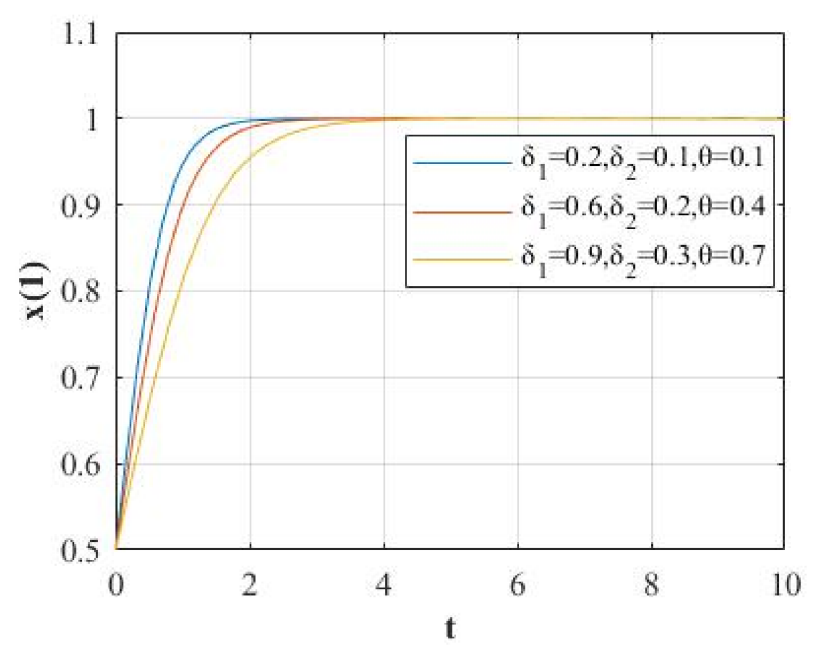

(a)

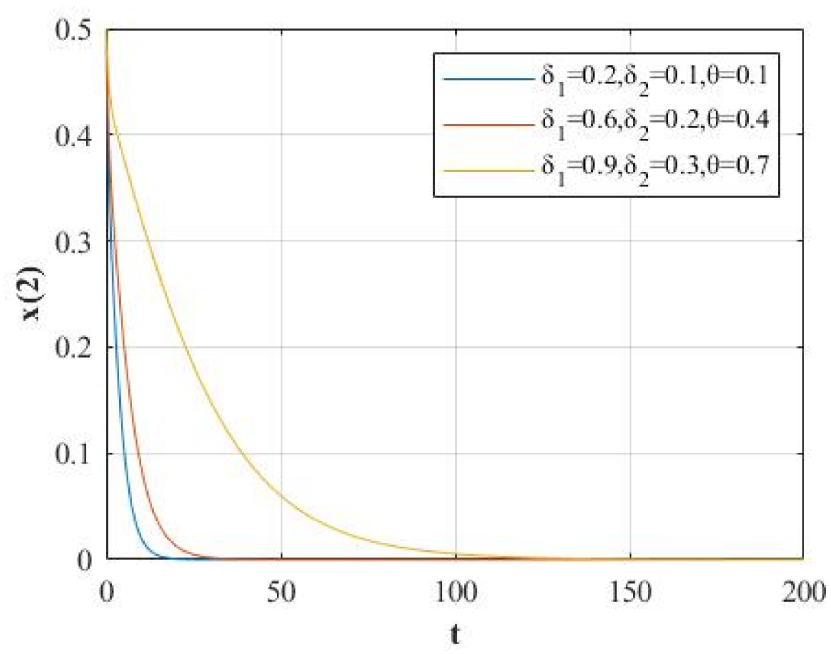

(b)

Figure 10. (a) While changing $\delta_{2}, \theta$, and $\delta_{1}$, evolution diagram of government's supervision option. (b) While changing $\delta_{2}, \theta$, and $\delta_{1}$, evolution diagram of platform's supervision option.

\subsection{Transaction Stage: The Evolutionary Game Process among the Live Streaming Platform,} Anchor and Consumer

The government and the live streaming platform are the key entities to promote the formation of live streaming governance rules and regulations. The choice of game strategies between the two affects the behavior of anchors and consumers in the transaction stage. The stable strategy formed by the government and the live streaming platform during the promotion process provides a good environment for live streaming transactions. As can be seen from Section 4.1, the online live streaming platform, anchors, and consumers are the core entities in the live streaming transaction, but the government is not directly involved in the actual transaction process. As a result, only the platform, anchor and consumers are considered during the live streaming transaction stage. Among them, the live streaming platform and the anchor are both "sellers", and their ultimate goal of participating in the live streaming is to maximize profits. Both of them may have moral hazards and risks in live streaming transactions. However, due to the different roles played by the live streaming platform and anchor, there is also a certain conflict in the relationship of interest between the two. Section 4 shows that in order to obtain more economic benefits, the anchor may violate market transaction rules (such as counterfeit and inferior products, low quality and high price) while providing and selling products. For consumers, the live streaming 
platform and the anchor are the "sellers" in the transaction. Once an illegal transaction occurs and is discovered by consumers, it will not only affect the anchor, but also affect the future purchase options of the live streaming platform. Therefore, the relationship of interests contains the conflict between the anchor and the platform: The anchor may violate the supervision, and the platform needs to conduct standardized supervision on him/her, and weighs the cost of supervision and the risk of non-supervision. Consumers will also consider whether to lodge a complaint with the relevant authorities for the anchor's violations, and participate in the environmental governance of live streaming, which also shows that the platform and consumers have a reciprocal preference for the anchor, i.e., the behavioral game strategies of the three are: live streaming platform (standardized operation, non-standardized operation), anchor (violating regulations, non-violating regulations), and consumers (participating in guidance, not participating in guidance).

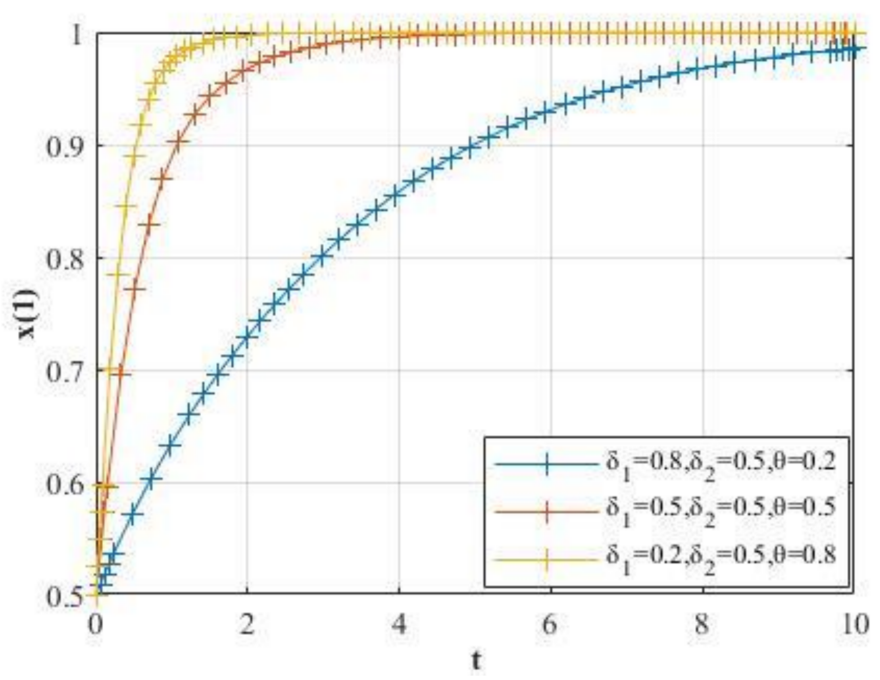

(a)

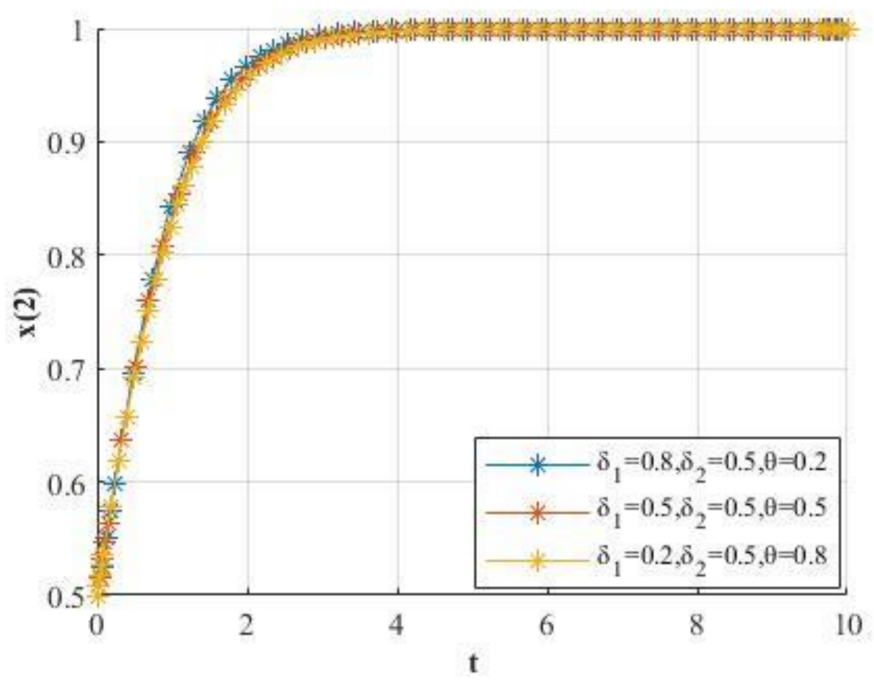

(b)

Figure 11. (a) While changing $\delta_{1}, \theta$, and $\delta_{2}=0.5$, evolution diagram of government's supervision option. (b) While changing $\delta_{1}, \theta$, and $\delta_{2}=0.5$, evolution diagram of platform's supervision option. 


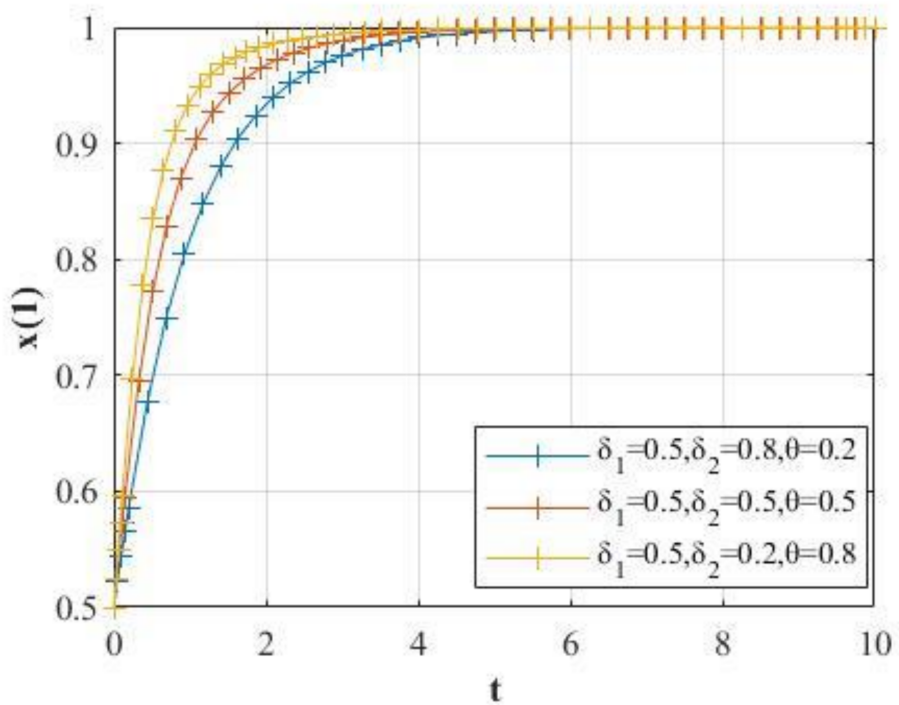

(a)

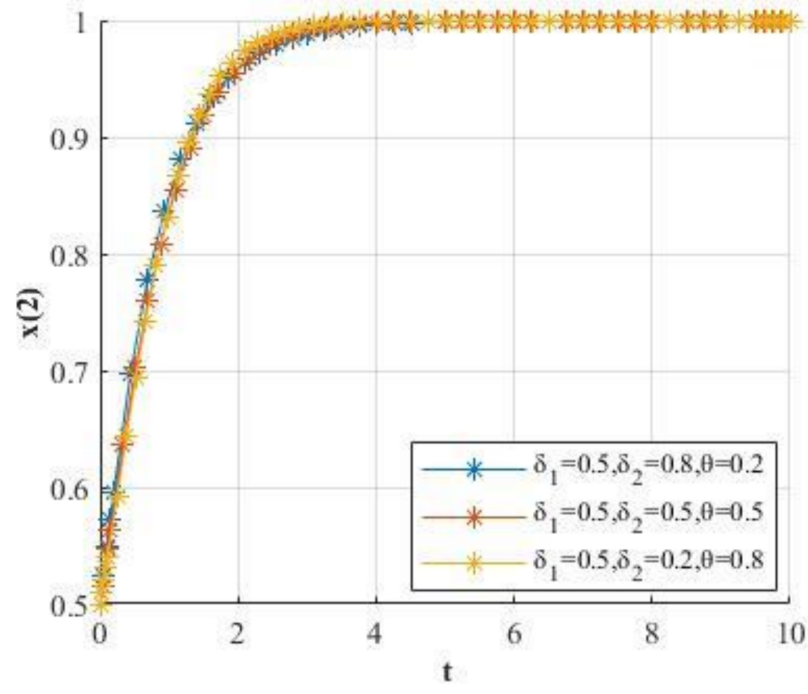

(b)

Figure 12. (a) While changing $\delta_{2}, \theta$, and $\delta_{1}=0.5$, evolution diagram of government's supervision option. (b) While changing $\delta_{2}, \theta$, and $\delta_{1}=0.5$, evolution diagram of platform's supervision option. 


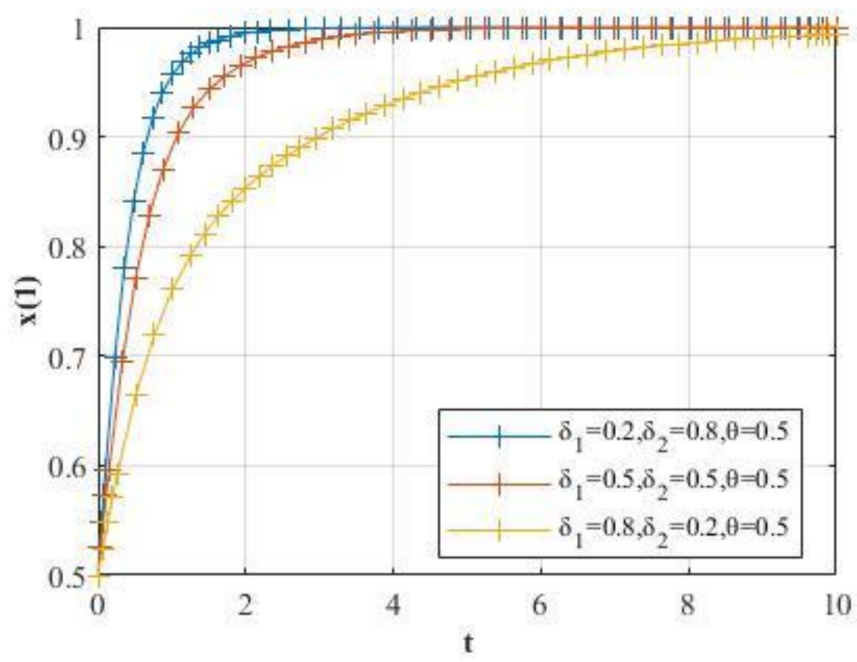

(a)

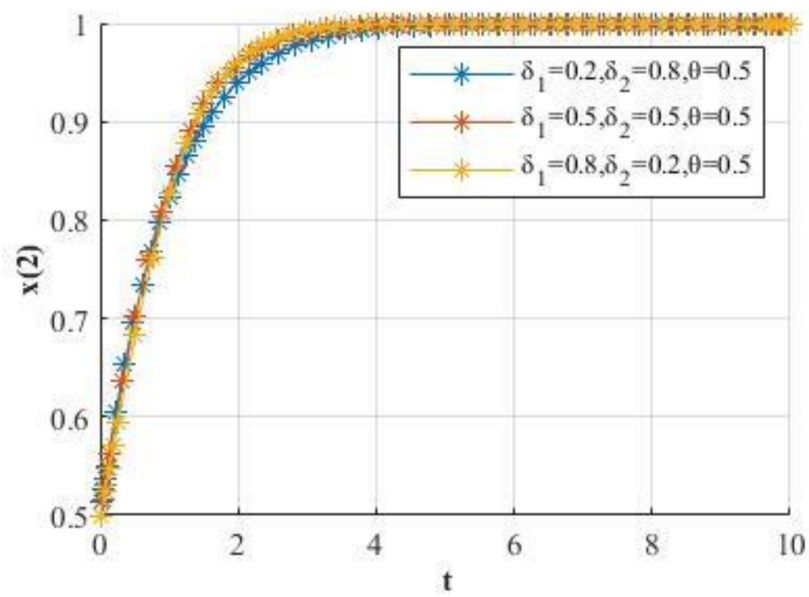

(b)

Figure 13. (a) While changing $\delta_{1}, \delta_{2}$, and $\theta=0.5$, evolution diagram of government's supervision option. (b) While changing $\delta_{1}, \delta_{2}$, and $\theta=0.5$, evolution diagram of platform's supervision option.

Rabin [49] and Levine [50] put forward a reciprocal altruistic behavior preference model: The utility function of participant $i$ depends on his own material payment and the material payment of its participants, namely:

$$
U_{i}=\pi_{i}+\Sigma \beta_{i j} \pi_{j}
$$

where $\pi_{i}$ and $\pi_{j}$ represent the material payment of participant $i$ and other participant $j=1$, $2, \ldots, n(j \neq i)$, respectively, and $\beta_{i j}$ represents the proportion of $j^{\prime}$ material payment in the weight of utility function of $i$, which should be satisfied:

$$
\beta_{i j}=\left(\alpha_{i}+\lambda_{i} \alpha_{j}\right) /\left(1+\lambda_{i}\right), j \neq i
$$

where $\alpha_{i}$ is in the interval $[-1,1], \lambda_{j} \geq 0$, and $\alpha_{i}$ is the goodwill and maliciousness degree of participant $i$ to other participants; $\alpha_{j}$ is in the interval $[-1,1]$, which is the goodwill degree of participant $i$ to $j ; \lambda_{i}$ represents the relevance of participant $i$ 's beliefs of other participants to their payment evaluation. In the process of live streaming, platforms, anchors, and consumers can take specific measures to change their own preferences and develop in a direction that is conducive to the governance of the live streaming environment. The corresponding measures are shown in Table 10. 
Table 10. Platform-anchor-consumer governance measures in the transaction stage of live streaming governance.

\begin{tabular}{|c|c|c|}
\hline Entity & Measure & Result \\
\hline \multirow{4}{*}{ Platform } & $\begin{array}{l}\text { Give more support and exposure to anchors with their own resources, but less } \\
\text { training and support for new anchors; the platform will deduct the gift income from } \\
\text { unsigned anchors, and the floating rewards of contracted individual anchors will be } \\
\text { reduced; the platform will provide less resources to promote the anchors }\end{array}$ & $\begin{array}{l}\text { Weakening platform's } \\
\text { altruistic preference }\end{array}$ \\
\hline & $\begin{array}{l}\text { Cultivate and introduce various industry anchors, and carry out high-quality training } \\
\text { programs for anchors; the platform provides assistance to the anchors with } \\
\text { operational skills and technical support; the platform rationally guides consumers and } \\
\text { organizes various activities to give the anchors more publicity and exposure, and } \\
\text { improve the number of fans; the platform sets up no-threshold registration for } \\
\text { supporting talents, and invests in exposure and rewards to stimulate the enthusiasm } \\
\text { of ordinary and new anchors }\end{array}$ & $\begin{array}{l}\text { Strengthening platform's } \\
\text { altruistic preference }\end{array}$ \\
\hline & $\begin{array}{l}\text { The platform reduces the behavioral supervision or qualification review of the anchor; } \\
\text { it fails to publicize the business information of the products sold on the platform in } \\
\text { accordance with the requirements of the regulatory authorities, and the attitude of } \\
\text { cooperating with the law enforcement authorities is relatively negative }\end{array}$ & $\begin{array}{l}\text { Weakening the } \\
\text { platform's reciprocal } \\
\text { preference }\end{array}$ \\
\hline & $\begin{array}{l}\text { The platform dynamically supervises the anchors, establishes a credit evaluation } \\
\text { system, blacklist system, formula system, and takes measures such as warning } \\
\text { reminders, restrictive functions, suspension of release, and cancellation of anchor } \\
\text { accounts with a large number of user complaints. Filing with relevant law } \\
\text { enforcement agencies; the platform should save and record live streaming content, } \\
\text { and the product and service transaction information in the live streaming content } \\
\text { should be kept for no less than three years. When consumer rights and interests are } \\
\text { infringed, assist users to provide necessary evidence to law enforcement agencies; } \\
\text { Perform corresponding review of the qualifications of the anchors stationed on the } \\
\text { platform and the anchor information needs to be recorded in real name. For the } \\
\text { anchors that do not meet the requirements, the corresponding live streaming services } \\
\text { are not provided, and the corresponding security guarantee obligations are assumed }\end{array}$ & $\begin{array}{l}\text { Strengthening the } \\
\text { platform's reciprocal } \\
\text { preference }\end{array}$ \\
\hline \multirow{2}{*}{ Anchor } & $\begin{array}{c}\text { In order to obtain more profits, the anchor may damage the commercial reputation } \\
\text { and product reputation of competitors, and make false or misleading commercial } \\
\text { publicity, sell fake and shoddy products, deceive and mislead consumers, directly } \\
\text { bundle or provide a variety of options such as bundled goods or services to the } \\
\text { consumers, gain more consumer attention through fraud, and use improper means to } \\
\text { conduct live streaming sales on multiple platforms }\end{array}$ & $\begin{array}{l}\text { Weakening anchor's } \\
\text { altruistic preference }\end{array}$ \\
\hline & $\begin{array}{l}\text { The anchor must know more about products and increase responsibility, strictly } \\
\text { distinguish the quality of the products, actively abide by the Consumer Rights } \\
\text { Protection Law, Product Quality Law, and other laws and regulations. When the } \\
\text { product has product quality problems, anchor should communicate with the merchant } \\
\text { timely and assume joint and several liabilities, and make corresponding compensation }\end{array}$ & $\begin{array}{l}\text { Strengthening anchor's } \\
\text { altruistic preference }\end{array}$ \\
\hline \multirow[t]{2}{*}{ Consumer } & $\begin{array}{l}\text { Consumers will be passionate about purchase due to the anchors' star effect, ultra-low } \\
\text { prices, limited time offers, and lack of judgment. Some consumers do not choose the } \\
\text { corresponding channel to protect own interest when they encounter counterfeit and } \\
\text { shoddy goods and after-sales service, instead, they bear the losses. In addition, } \\
\text { consumers delete the true feedback of the products due to the discounts given by the } \\
\text { anchor or the merchant }\end{array}$ & $\begin{array}{l}\text { Weakening consumer's } \\
\text { altruistic preference }\end{array}$ \\
\hline & $\begin{array}{l}\text { Establish a rational consumption concept, avoid blind conformity, and strengthen own } \\
\text { legal awareness of rights protection, check the business information published on the } \\
\text { platform before purchase, avoid goods without a business license, do not listen to the } \\
\text { anchor's inducement to transfer privately, keep all vouchers for on-duty transaction } \\
\text { and payment (once their rights and interests are damaged, consumers can use them as } \\
\text { evidence of rights protection). When consumers are infringed on their rights, they can } \\
\text { be conducted on platforms with greater influence such as Black Cat complaints, } \\
\text { Weibo, and Zhihu to reduce other consumers' damage }\end{array}$ & $\begin{array}{l}\text { Strengthening } \\
\text { consumer's altruistic } \\
\text { preference }\end{array}$ \\
\hline
\end{tabular}


Table 10. Cont.

\begin{tabular}{|c|c|c|}
\hline Entity & Measure & Result \\
\hline & $\begin{array}{c}\text { When the rights and interests of consumers are infringed, the consumers do not have } \\
\text { the awareness of rights protection, or seek corresponding compensation from anchors } \\
\text { and platforms }\end{array}$ & $\begin{array}{l}\text { Weakening the } \\
\text { consumer's reciprocal } \\
\text { preference }\end{array}$ \\
\hline & $\begin{array}{l}\text { When consumers find suspected infringement of consumer rights and interests in the } \\
\text { live streaming, they should save relevant evidence timely through screenshots, screen } \\
\text { recordings, etc., and complain to the online live streaming platform. Consumers can } \\
\text { claim compensation for the loss after purchasing defected goods }\end{array}$ & $\begin{array}{l}\text { Strengthening } \\
\text { consumer's reciprocal } \\
\text { preference }\end{array}$ \\
\hline
\end{tabular}

The game process between the three is discussed based on formulas (8)-(9). Assuming that when the anchor has behaved in good faith, i.e., when the anchor did not violate the rules, the reciprocal preference of the platform and consumers was set to 0 . The strategy set of the live streaming platform was (standardized operation, non-standardized operation), the strategy set of the anchor was (standardized performance, non-standardized performance), and the strategy set of the consumer was (participating in the guidance, not participating in the guidance). The specific game process is shown in Figure 14. According to the reciprocal altruistic behavior preference model proposed by Rabin and Levine, the profit risk matrix of three entities and the related parameters involved in the game process of the "live streaming platform-anchor-consumer" were set up, as shown in Tables 11 and 12.

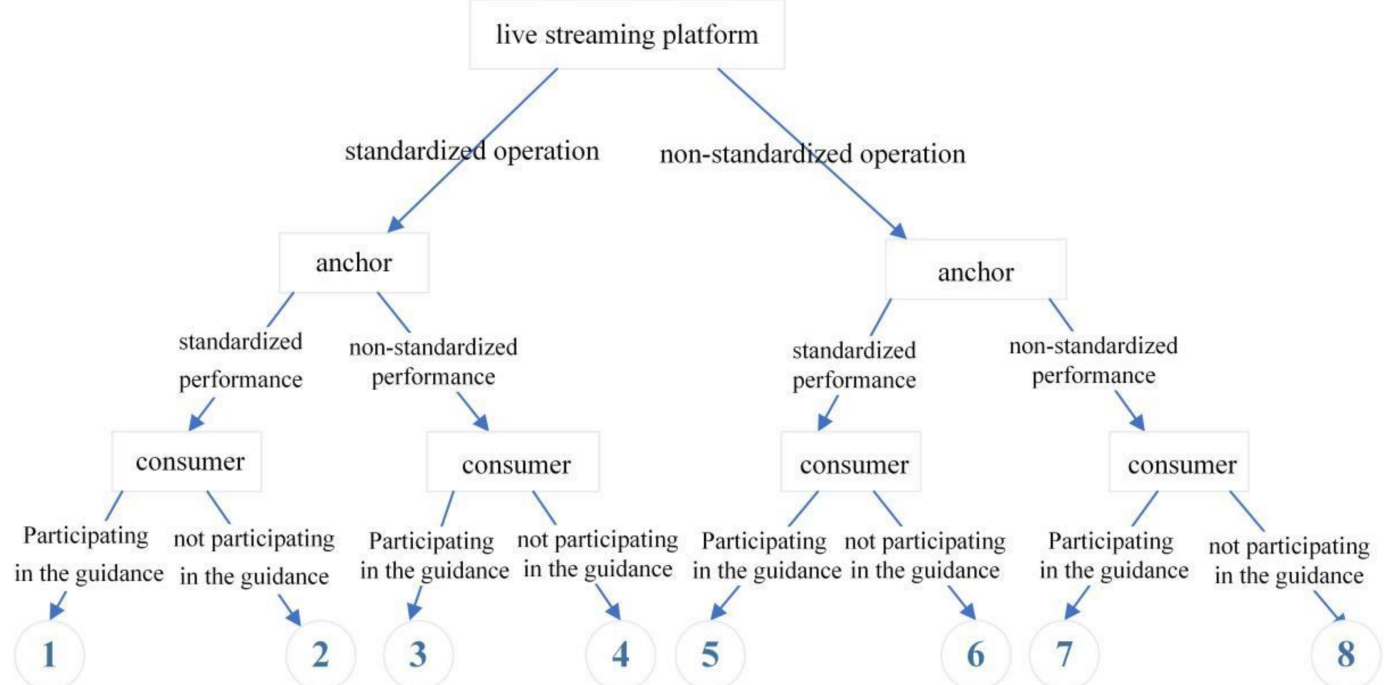

Figure 14. Game tree of "live streaming platform-anchor-consumer".

Table 11. Definition of parameters involved in the game process between government and online live streaming platform.

\begin{tabular}{cr}
\hline Parameter & Definition \\
\hline$P_{2}$ & Profit of live streaming platform with standardized operation \\
\hline$P_{3}$ & Profit of live streaming platform with non-standardized operation \\
\hline$C_{2}$ & Cost of live streaming platform with standardized operation \\
\hline$S_{3}$ & $\begin{array}{r}\text { Social profit loss of live streaming platform with non-standardized operation } \\
\text { due to anchor's non-standardized behavior }\end{array}$ \\
\hline$P_{5}$ & $\begin{array}{c}\text { Penalty of anchor due to anchor's non-standardized behavior in live streaming } \\
\text { platform with standardized operation }\end{array}$ \\
\hline
\end{tabular}


Table 11. Cont.

\begin{tabular}{|c|c|}
\hline Parameter & Definition \\
\hline$S_{4}$ & $\begin{array}{l}\text { Loss of live streaming platform with non-standardized operation due to } \\
\text { anchor's non-standardized behavior (such as fines imposed by government } \\
\text { regulatory authorities and loss of potential customers) }\end{array}$ \\
\hline$P_{6}$ & Profit of anchor with standardized performance \\
\hline$P_{7}$ & Profit of anchor with non-standardized performance \\
\hline$S_{5}$ & $\begin{array}{l}\text { Losses of anchor's non-standardized behavior found by live streaming platform } \\
\text { with standardized operation }\end{array}$ \\
\hline$S_{6}$ & $\begin{array}{l}\text { When the anchor provides non-standardized performance, consumers } \\
\text { participate in leading the chaos of the live streaming and report it. At this time, } \\
\text { the loss suffered by the anchor (for example, consumers complain, which leads } \\
\text { them to no longer buy goods from the anchor, and serious cases lead to public } \\
\text { opinion or regulatory authorities to fine or remove them from the shelves, etc.) }\end{array}$ \\
\hline$S_{7}$ & $\begin{array}{l}\text { Loss of consumers caused by anchor's non-standardized behavior (worse good } \\
\text { and service quality) }\end{array}$ \\
\hline$C_{3}$ & Cost of guiding standardized live streaming of anchor by consumers \\
\hline$P_{8}$ & Profit of guiding standardized live streaming by consumers \\
\hline$\lambda_{1}$ & Degree of platform's reciprocal preference \\
\hline$\lambda_{2}$ & Degree of consumer's reciprocal preference \\
\hline$\delta_{2}$ & Degree of platform's altruistic preference \\
\hline$\delta_{3}$ & Degree of anchor's altruistic preference \\
\hline$\delta_{4}$ & Degree of consumer's altruistic preference \\
\hline$y$ & Probability of live streaming platform with standardized operation \\
\hline$z$ & Probability of anchor without non-standardized performance \\
\hline$w$ & Probability of guiding by consumer \\
\hline
\end{tabular}

Table 12. The return and risk matrix of "network live streaming platform-anchor-consumer".

\begin{tabular}{|c|c|c|c|}
\hline Strategy & $\begin{array}{l}\text { Live Streaming } \\
\text { Platform }\end{array}$ & Anchor & Consumer \\
\hline $\begin{array}{l}\text { (standardized, } \\
\text { non-standardized, } \\
\text { guiding) }\end{array}$ & $P_{2}-C_{2}+\delta_{2} P_{6}$ & $\begin{array}{c}P_{6}+\delta_{3}\left(P_{2}-C_{2}+P_{8}\right. \\
\left.-C_{3}\right)\end{array}$ & $P_{8}-C_{3}+\delta_{4} P_{6}$ \\
\hline $\begin{array}{l}\text { (standardized, } \\
\text { non-standardized, } \\
\text { non-guiding) }\end{array}$ & $P_{2}-C_{2}+\delta_{2} P_{6}$ & $P_{6}+\delta_{3}\left(P_{2}-C_{2}\right)$ & 0 \\
\hline $\begin{array}{l}\text { (non-standardized, } \\
\text { non-standardized, } \\
\text { guiding) }\end{array}$ & $P_{3}+\delta_{2} P_{6}$ & $P_{6}+\delta_{3}\left(P_{3}+P_{8}-C_{3}\right)$ & $P_{8}-C_{3}$ \\
\hline $\begin{array}{l}\text { (non-standardized, } \\
\text { non-standardized, } \\
\text { non-guiding) }\end{array}$ & $P_{3}+\delta_{2} P_{6}$ & $P_{6}+\delta_{3} P_{3}$ & 0 \\
\hline $\begin{array}{l}\text { (standardized, } \\
\text { non-standardized, } \\
\text { guiding) }\end{array}$ & $\begin{array}{c}P_{2}+P_{5}-C_{2}-S_{4}+ \\
\frac{\delta_{2}+\delta_{3} \lambda_{1}}{1+\lambda_{1}}\left(P_{7}-S_{5}-S_{6}\right)\end{array}$ & $\begin{array}{c}P_{7}-S_{5}-S_{6}+ \\
\delta_{3}\left(P_{2}+P_{5}-C_{2}-S_{4}\right. \\
\left.+P_{8}-C_{3}-S_{7}\right)\end{array}$ & $\begin{array}{c}P_{8}-C_{3}-S_{7+} \\
\frac{\delta_{4}+\delta_{3} \lambda_{2}}{1+\lambda_{2}}\left(P_{7}-S_{5}-S_{6}\right)\end{array}$ \\
\hline $\begin{array}{l}\text { (standardized, } \\
\text { non-standardized, } \\
\text { non-guiding) }\end{array}$ & $\begin{array}{c}P_{2}+P_{5}-C_{2}-S_{4}+ \\
\frac{\delta_{2}+\delta_{3} \lambda_{1}}{1+\lambda_{1}}\left(P_{7}-S_{5}\right)\end{array}$ & $\begin{array}{c}P_{7}-S_{5}+\delta_{3}\left(P_{2}+P_{5}\right. \\
\left.-C_{2}-S_{4}\right)\end{array}$ & $\frac{\delta_{4}+\delta_{3} \lambda_{2}}{1+\lambda_{2}}\left(P_{7}-S_{5}\right)$ \\
\hline
\end{tabular}


Table 12. Cont.

\begin{tabular}{cccc}
\hline Strategy & $\begin{array}{c}\text { Live Streaming } \\
\text { Platform }\end{array}$ & Anchor & Consumer \\
\hline $\begin{array}{c}\text { (non-standardized, } \\
\text { non-standardized, } \\
\text { guiding) }\end{array}$ & $\begin{array}{c}P_{3}-S_{3}+\frac{\delta_{2}+\delta_{3} \lambda_{1}}{1+\lambda_{1}}\left(P_{7}\right. \\
\left.-S_{6}\right)\end{array}$ & $\begin{array}{c}P_{7}-S_{6}+\delta_{3}\left(P_{3}-S_{3}\right. \\
\left.+P_{8}-C_{3}-S_{7}\right)\end{array}$ & $\begin{array}{c}P_{8}-C_{3}-S_{7} \lambda_{2} \\
1+\lambda_{2}\end{array}$ \\
\hline $\begin{array}{c}\text { (non-standardized, } \\
\text { non-standardized, } \\
\text { non-guiding) }\end{array}$ & $P_{3}-S_{3}+\frac{\delta_{2}+\delta_{3} \lambda_{1}}{1+\lambda_{1}} P_{7}$ & $P_{7}+\delta_{3}\left(P_{3}-S_{3}\right)$ & $\frac{\delta_{4}+\delta_{3} \lambda_{2}}{1+\lambda_{2}} P_{7}$ \\
\hline
\end{tabular}

\subsubsection{Equilibrium Analysis of Evolutionary Game}

According to Table 12, the dynamic replication equation of the live streaming platform, the anchor, and the consumer was obtained, assuming $\lambda_{1}{ }^{*}=\frac{\delta_{2}+\delta_{3} \lambda_{1}}{1+\lambda_{1}}$, and $\lambda_{2}{ }^{*}=\frac{\delta_{4}+\delta_{3} \lambda_{2}}{1+\lambda_{2}}$.

Dynamic replication equation of the live streaming platform is

$$
\mathrm{G}(y)=\frac{d y}{d t}=y(1-y)\left[z\left(S_{4}+\lambda_{1}{ }^{*} S_{5}\right)+P_{2}+P 5-C 2-S 4-P_{3}+S 3-\lambda_{1}{ }^{*} S_{5}\right]
$$

Dynamic replication equation of the anchor is

$$
\mathrm{H}(z)=\frac{d z}{d t}=z(1-z)\left\{y\left[S 5-\delta_{3}\left(P 5-S_{4}+S_{3}\right)\right]+\mathrm{w}\left(S_{6}+\delta_{3} S_{7}\right)+P 6-P_{7}+\delta_{3} C_{3}\right\}
$$

Dynamic replication equation of the consumer is

$$
\mathrm{K}(w)=\frac{d w}{d t}=w(1-w)\left[z y \delta_{4} P_{6}+z\left(S_{7}+\lambda_{2}{ }^{*} S_{6}\right)+P 8-C 3-S_{7}-\lambda_{2}{ }^{*} S_{6}\right]
$$

Assuming $\mathrm{G}(y)=0, \mathrm{H}(z)=0, \mathrm{~K}(w)=0,9$ local equilibrium points of the system can be obtained: $(0,0,0),(0,0,1),(0,1,0),(1,0,0),(0,1,1),(1,0,1),(1,1,0),(1,1,1),\left(z^{*}, y^{*}, w^{*}\right)$

$$
\left\{\begin{array}{c}
z^{*}=\frac{-P_{2}-P_{5}+C_{2}+S_{4}+\lambda_{1} * S_{5}+P_{3}-S_{3}}{S_{4}+\lambda_{1} * S_{5}} \\
y^{*}=\frac{-P_{8}+C_{3}+S_{7}+\lambda_{2} S_{6}-z\left(S_{7}+\lambda_{2}{ }^{*} S_{6}\right)}{z \delta_{4} P_{6}} \\
w^{*}=\frac{-P_{6}+P_{7}-\delta_{3} C_{3}-y\left[S_{5}-\delta_{3}\left(P_{5}-S_{4}+S_{3}\right)\right]}{S_{6}+\delta_{3} S_{7}}
\end{array}\right.
$$

Similar to the stable solution process of the local equilibrium point in Section 4.1.1, when 9 local equilibrium points meet $\operatorname{Det} J>0$ and $\operatorname{Tr} J<0$, equilibrium points will be created. The Jacobian Matrix of the system is:

$$
\begin{gathered}
(1-2 y)\left(z\left(S_{4}+\lambda_{1} * S_{5}\right)+P_{2}\right. \\
\left.+P_{5}-C_{2}-S_{4}-P_{3}+S_{3}-\lambda_{1}{ }^{*} S_{5}\right) \\
z(1-z)\left[S_{5}-\delta_{3}\left(P_{5}-S_{4}+S_{3}\right)\right] \\
w(1-w) z \delta_{4} P_{6}
\end{gathered}
$$$$
J=\left[\begin{array}{lll}
\frac{\partial G(y)}{\partial y} & \frac{\partial G(y)}{\partial z} & \frac{\partial G(y)}{\partial w} \\
\frac{\partial H(z)}{\partial y} & \frac{\partial H(z)}{\partial z} & \frac{\partial H(z)}{\partial w} \\
\frac{\partial K(w)}{\partial y} & \frac{\partial K(w)}{\partial z} & \frac{\partial K(w)}{\partial w}
\end{array}\right]=
$$$$
y(1-y)\left(S_{4}+\lambda_{1}^{*} S 5\right)
$$$$
(1-2 z)\left\{y\left[S_{5}-\delta_{3}\left(P_{5}-S_{4}+S_{3}\right)\right]\right.
$$$$
\left.+w\left(S_{6}+\delta_{3} S_{7}\right)+P_{6}-P_{7}+\delta_{3} C_{3}\right\}
$$$$
w(1-w) y \delta_{4} P_{6}
$$

$$
\left.\begin{array}{c}
z(1-z)\left(S_{6}+\delta_{3} S_{7}\right) \\
(1-2 w)\left[z y \delta_{4} P_{6}+z\left(S_{7}+\lambda_{2}{ }^{*} S_{6}\right)\right. \\
\left.+P_{8}-C_{3}-S_{7}-\lambda_{2} S_{6}\right]
\end{array}\right]
$$

According to calculation, only when $(1,0,0)$ meets $\lambda_{1}{ }^{*}>\frac{P_{2}-C_{2}-\left(P_{3}-S_{3}\right)+P_{5}-S_{4}}{S_{5}}$, ESS will be created. Next, simulation results were used to analyze the influence of the different preferences of the three types of subjects on the evolutionary stability strategy under this equilibrium point. 


\subsubsection{Classification of User Requirements}

Combined with the actual situation of live streaming and literature [22], each parameter assignment was as follows: $\mathrm{P}_{2}=5.5, \mathrm{P}_{3}=3.5, \mathrm{C}_{2}=4, \mathrm{~S}_{3}=2.5, \mathrm{P}_{5}=0.8, \mathrm{~S}_{4}=1.2$, $\mathrm{P}_{6}=2, \mathrm{P}_{7}=3.5, \mathrm{~S}_{5}=1.2, \mathrm{~S}_{6}=1.5, \mathrm{~S}_{7}=1.2, \mathrm{C}_{3}=0.5, \mathrm{P}_{8}=1.5$. (In the following analysis, the subject's preference value approaches 1 indicating to strengthen this preference, and the value approaches 0 indicating to weaken this preference), and the initial value of $(y, z, w)$ is $(0.5,0.5,0.5)$. According to the analysis in Section 5.2.1, the equilibrium point $(1,0,0)$ needs to meet the preconditions: $\lambda_{1}{ }^{*}>\frac{P_{2}-C_{2}-\left(P_{3}-S_{3}\right)+P_{5}-S_{4}}{S_{5}}$. Among them, both the anchor and the consumer may have egoistic preferences, that is, there is $\delta_{3}=0$ or $\delta_{4}=0$. The following will discuss whether the anchor and the consumer have egoistic preferences: (1) Neither the anchors nor the consumers hold social preferences; (2) the anchors do not hold social preferences; (3) consumers do not hold social preferences; (4) both anchors and consumers hold social preferences.

(1) Neither the anchors nor the consumers hold social preferences, and $\delta_{3}=0, \delta_{4}=0$, $\lambda_{2}=0$

From Figures 15 and 16, we can see that weakening the strength of the platform's altruistic preference was conducive to accelerating the standardized operation of the platform, while changing the degree of reciprocal preference of the platform would not have any impact on the behavior of anchors and consumers.

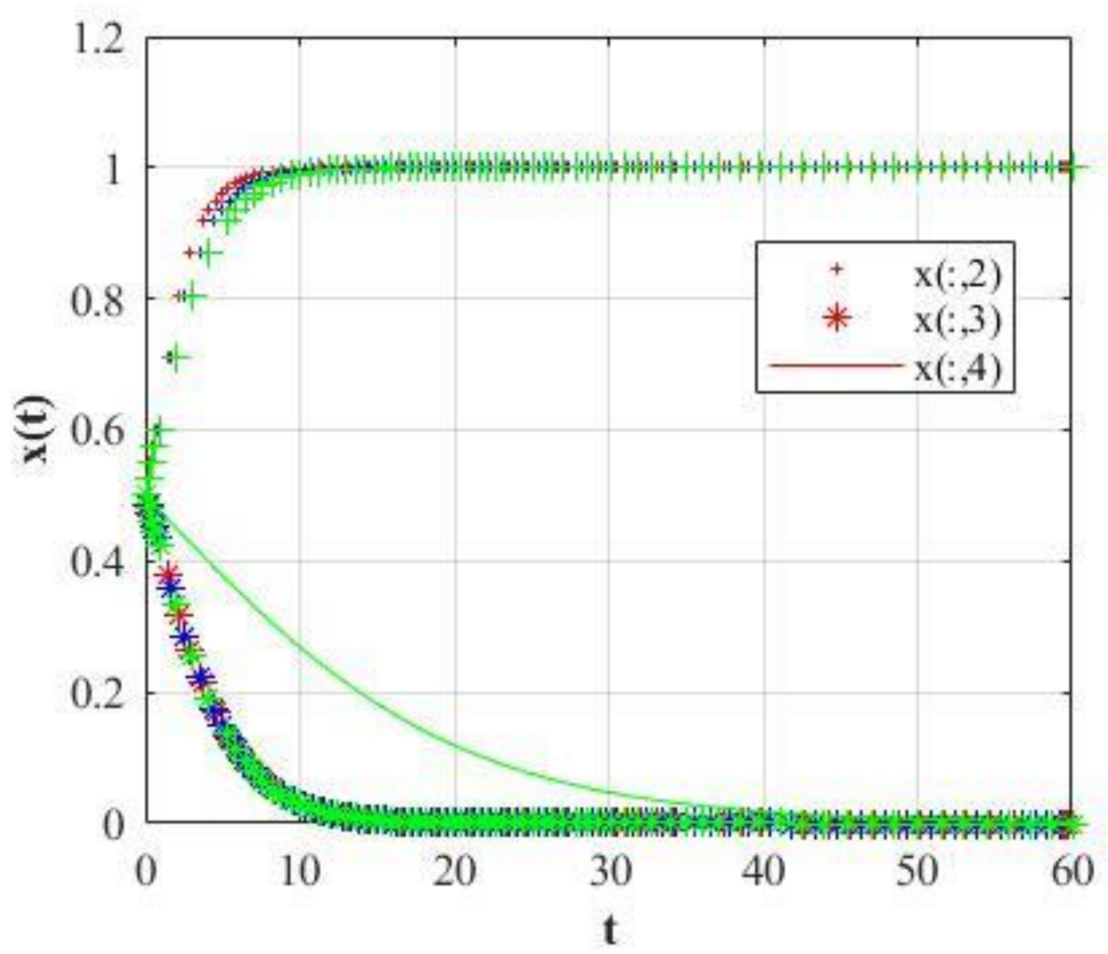

Figure 15. Change the parameter $\delta_{2}=0.2$ (red curve), 0.6 ((blue curve), 0.9 (green curve) to take the value of the three-way strategy evolution diagram. 


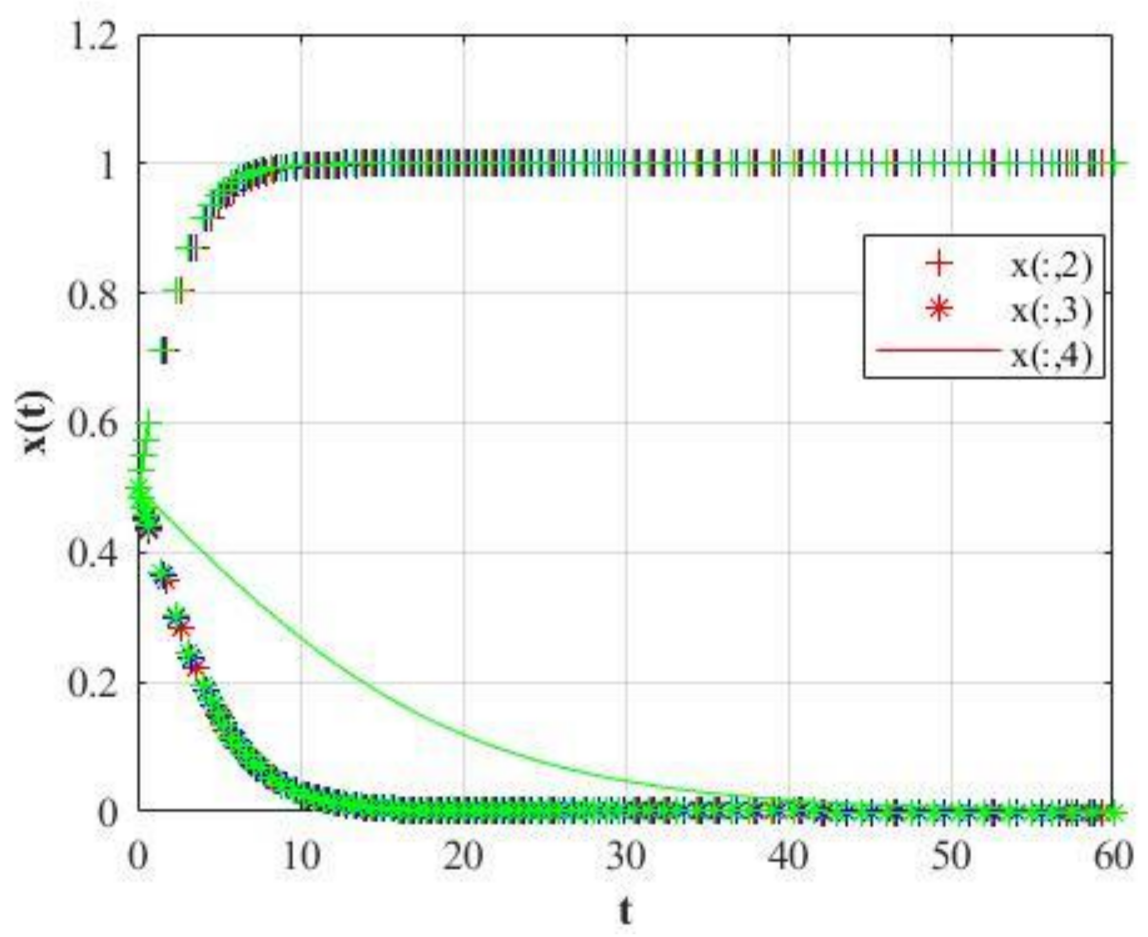

Figure 16. Change the parameter $\lambda_{1}=0.2$ (red curve), 0.6 ((blue curve), 0.9 (green curve) to take the value of the three-way strategy evolution diagram.

(2) The anchors do not hold social preferences, $\delta_{3}=0$

The simulation process mainly adjusts $\delta_{2}, \delta_{4}, \lambda_{1}, \lambda_{2}$ to test the influence of the degree of altruistic preference and reciprocity preference of different subjects on the governance of live streaming. Because there are many types of adjustments, only some examples are given below.

When the anchor does not hold social preferences, there are 13 simulation results, and some of the results are shown in Figures 17-20. From the simulation results, it can be seen that anchors will not easily change their behavior when they have egoism preferences, because the benefits of non-standardized performance are far greater than standardized performance. For example, the income of the anchors mainly depends on the "reward" of users, i.e., the purchase of "gifts" on the live streaming platform. At this time, higher popularity and more fans bring more income. Such a profit model can easily drive anchors to provide non-standardized performances (pornography, violence, etc.) to gain attention and increase revenue. To control the chaos in live streaming, it is necessary to play the role of consumers, strengthen consumers' altruistic preferences and weaken the strength of the altruistic preference of the platform, so that the platform can accelerate the evolution of standardized operation strategies and allow consumers' behavioral strategies from "non-guiding" to "guiding". 


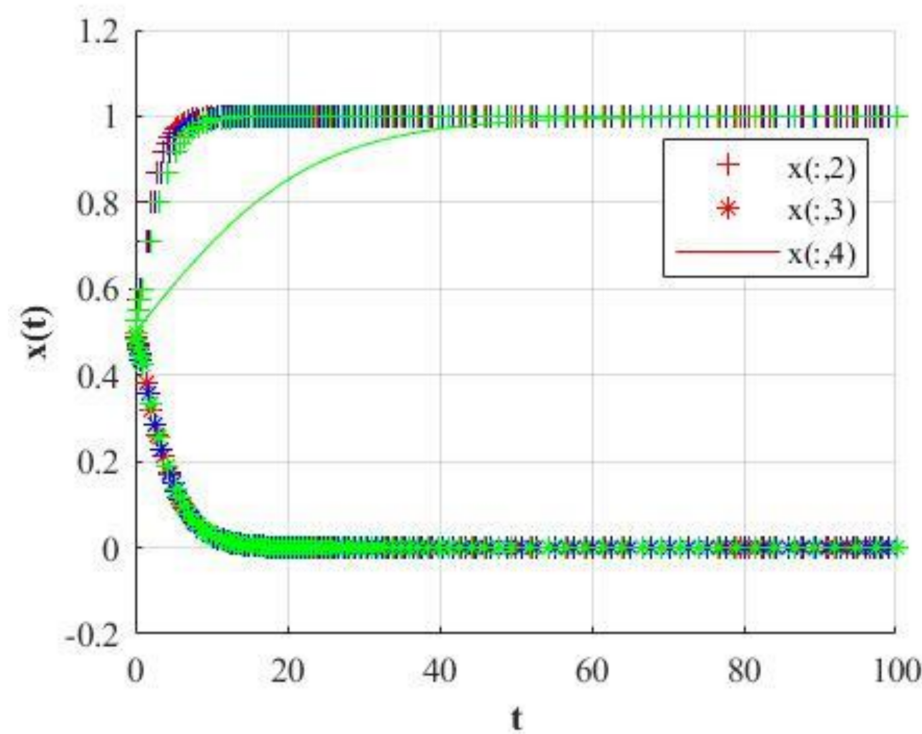

Figure 17. Change the parameter $\delta_{2}=0.2$ (red curve), 0.6 ((blue curve), 0.9 (green curve) to take the value of the three-way strategy evolution diagram.

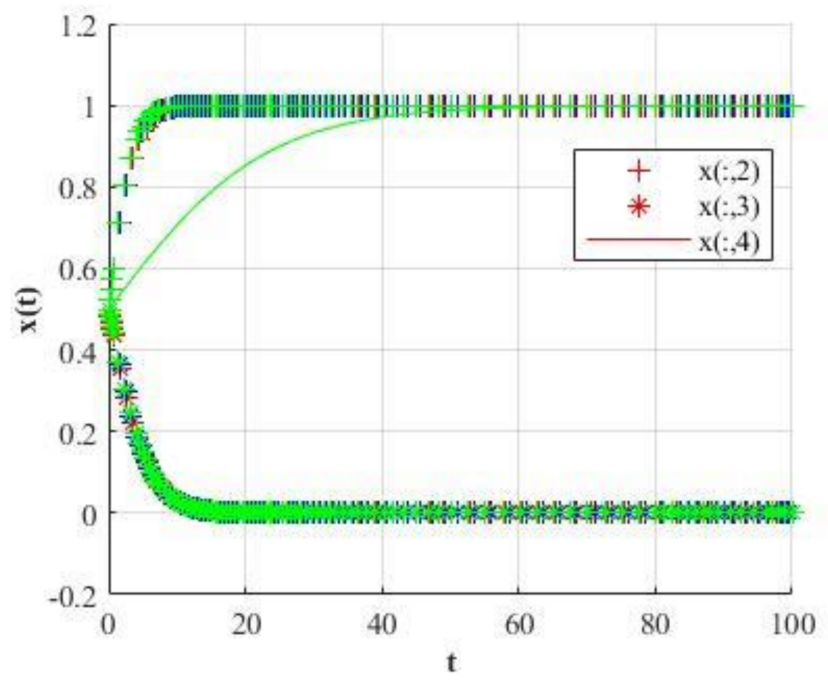

Figure 18. Change the parameter $\lambda_{1}=0.2$ (red curve), 0.6 (blue curve), 0.9 (green curve) to take the value of the three-way strategy evolution diagram. 


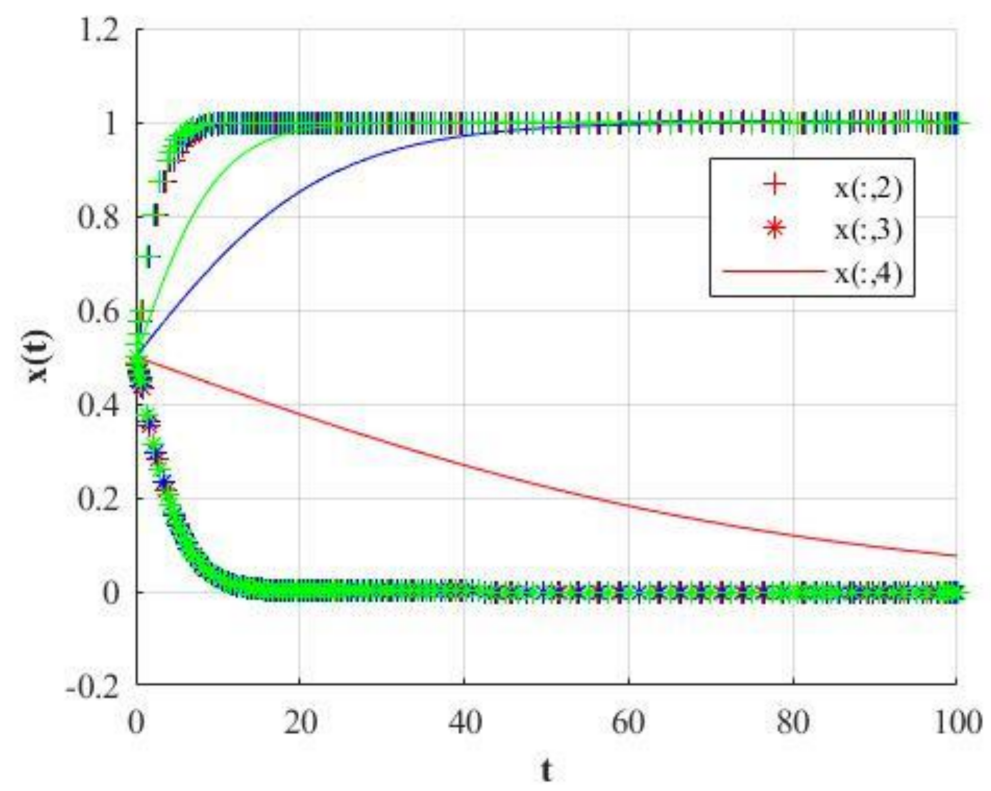

Figure 19. Change the parameter $\delta_{2}, \delta_{4}, \lambda_{1}=(0.8,0.2,0.8)$ red curve, $(0.5,0.5,0.5)$ blue curve, $(0.2,0.8,0.2)$ green curve to take the value of the three-way strategy evolution diagram.

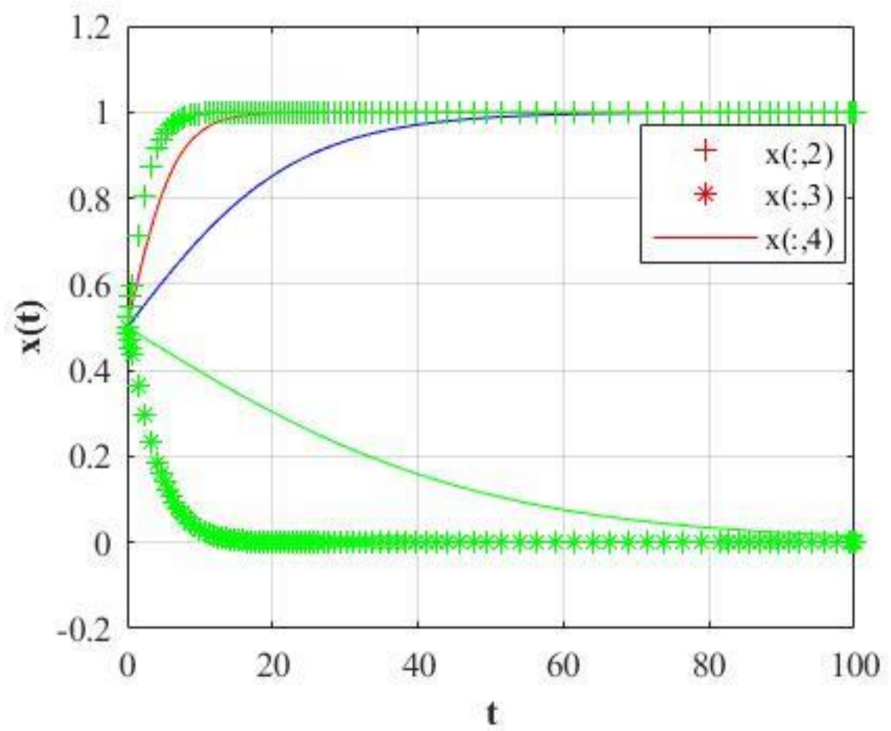

Figure 20. Change the parameter $\delta_{4}, \lambda_{2}=(0.8,0.2)$ red curve, $(0.5,0.5)$ blue curve, $(0.2,0.8)$ green curve to take the value of the three-way strategy evolution diagram.

(3) Consumers hold egoism preferences, and $\delta_{4}=0, \lambda_{2}=0$

The simulation process mainly adjusts $\delta_{2}, \delta_{3}, \lambda_{1}$ to test the influence of the degree of altruistic preference and reciprocal preference of different subjects on the governance of live streaming. Because there are many types of adjustments, only some examples are given below.

If consumers have egoism preferences, there are 6 simulation results. Figures 21 and 22 show two types of results. The two figures illustrate that the anchor's degree of altruistic preference is strengthened and the behavior strategy is changed from "non-standardized" to "standardized". At this time, it is conducive to constructing a good live streaming environment. Strengthening the degree of reciprocal preference of consumers has no impact on the behavior evolution strategies of the three. 


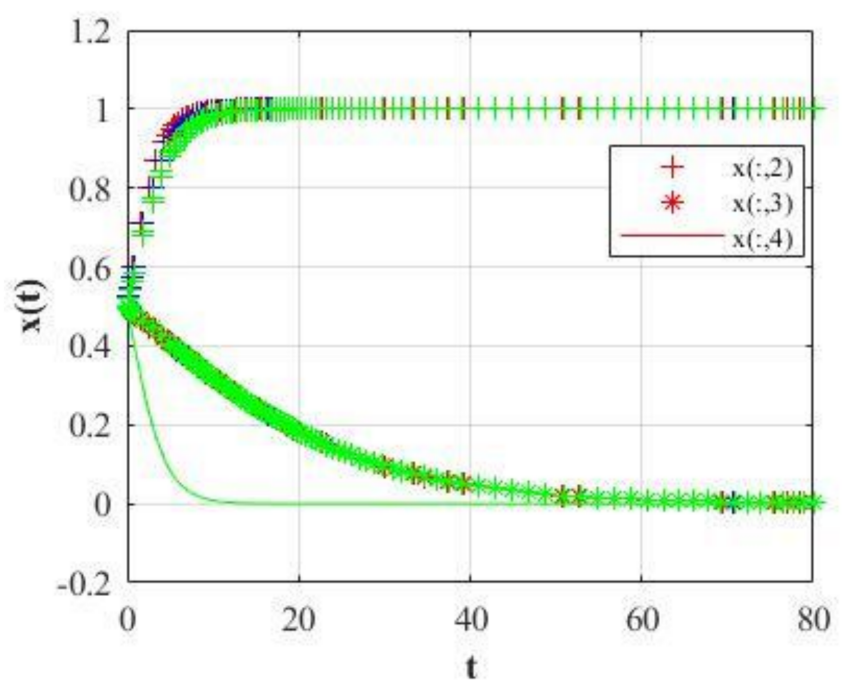

Figure 21. Change the parameter $\delta_{2}=0.2$ (red curve), 0.6 ((blue curve), 0.9 (green curve) to take the value of the three-way strategy evolution diagram.

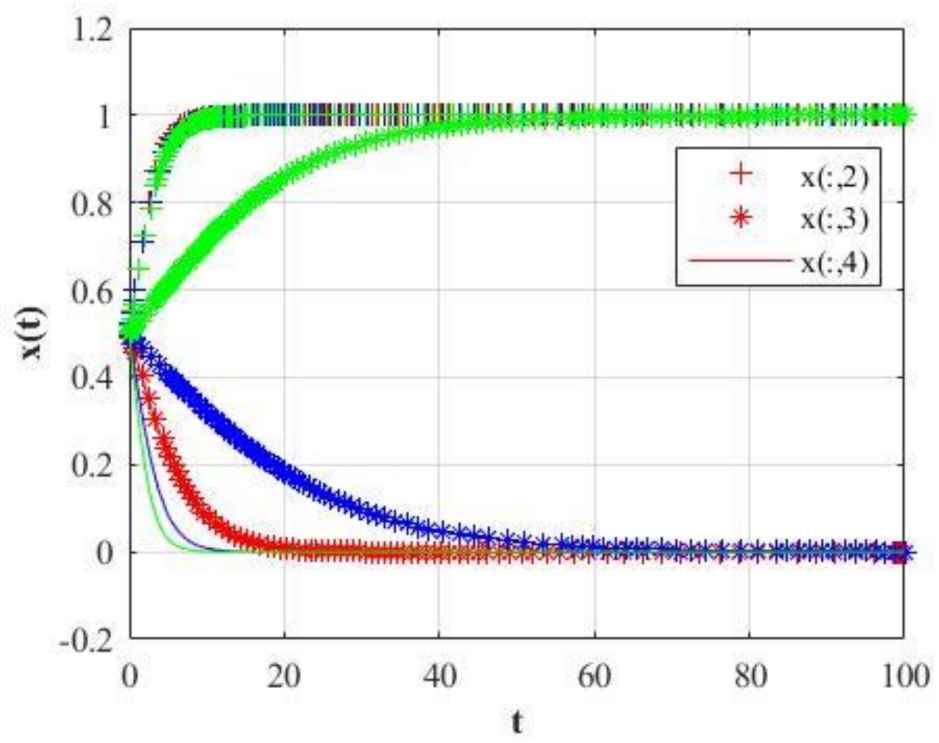

Figure 22. Change the parameter $\lambda_{1}$ and $\delta_{3}$ and their values are $(0.8,0.2)$ (red curve), $(0.5,0.5)$ (blue curve), and $(0.2,0.8)$ (green curve) so as to take the value of the three-way strategy evolution diagram.

(4) Both anchors and consumers hold social preferences, and $\delta_{3} \neq 0, \delta_{4} \neq 0$

The simulation process mainly adjusts $\delta_{2}, \delta_{4}, \delta_{3}, \lambda_{1}, \lambda_{2}$ to test the influence of the degree of altruistic preference and reciprocal preference of different subjects on the governance of live streaming. Because there are many types of adjustments, only some examples are given below.

If the three parties have social preferences, there are 22 simulation results, and some of the results are shown in Figures 23 and 24. When the anchors and consumers do not hold egoism preferences, changing the strength of reciprocal preference between the two will not improve live streaming environment. However, weakening the altruistic preference of the anchor while strengthening the altruistic preference of consumers can encourage consumers to participate in the environmental governance of guiding the live streaming, but the anchor's behavior strategy cannot reach an evolutionary equilibrium state. Weakening platform's altruistic preference while strengthening the anchor's altruistic preference can improve the anchor's non-standardized performance and accelerate platform to reach a 
stable state with standardized operation, but for consumers, it does not encourage them to participate in the governance of live streaming.

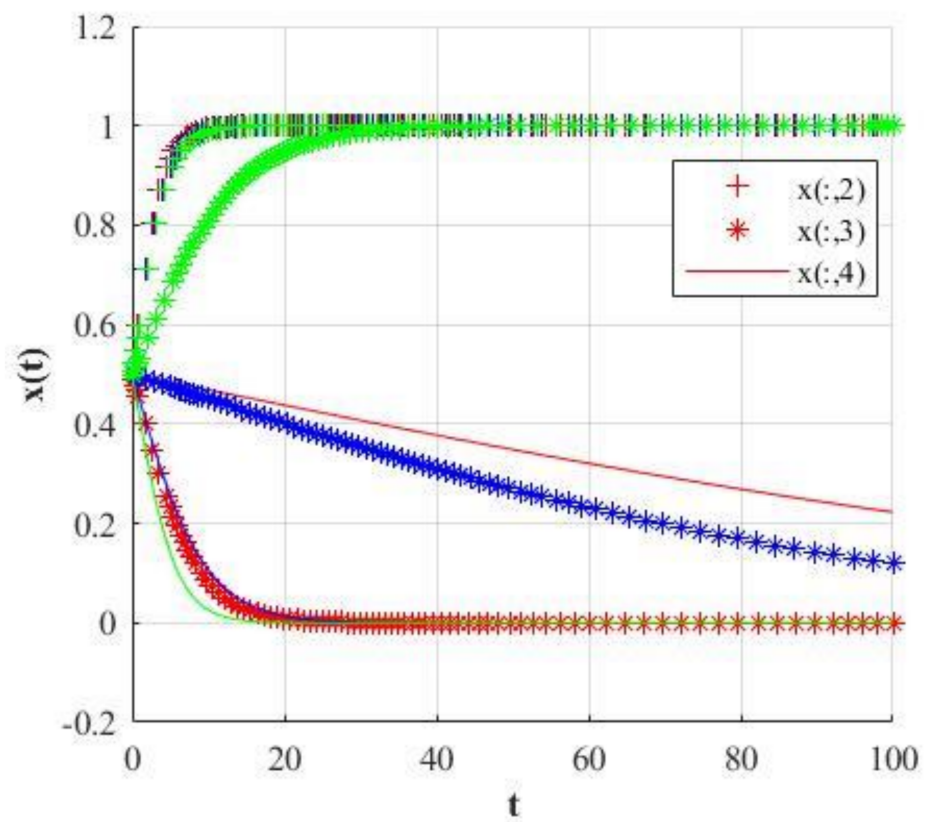

Figure 23. Change the parameter $\delta_{2}=0.2$ (red curve), 0.6 ((blue curve), 0.9 (green curve) to take the value of the three-way strategy evolution diagram.

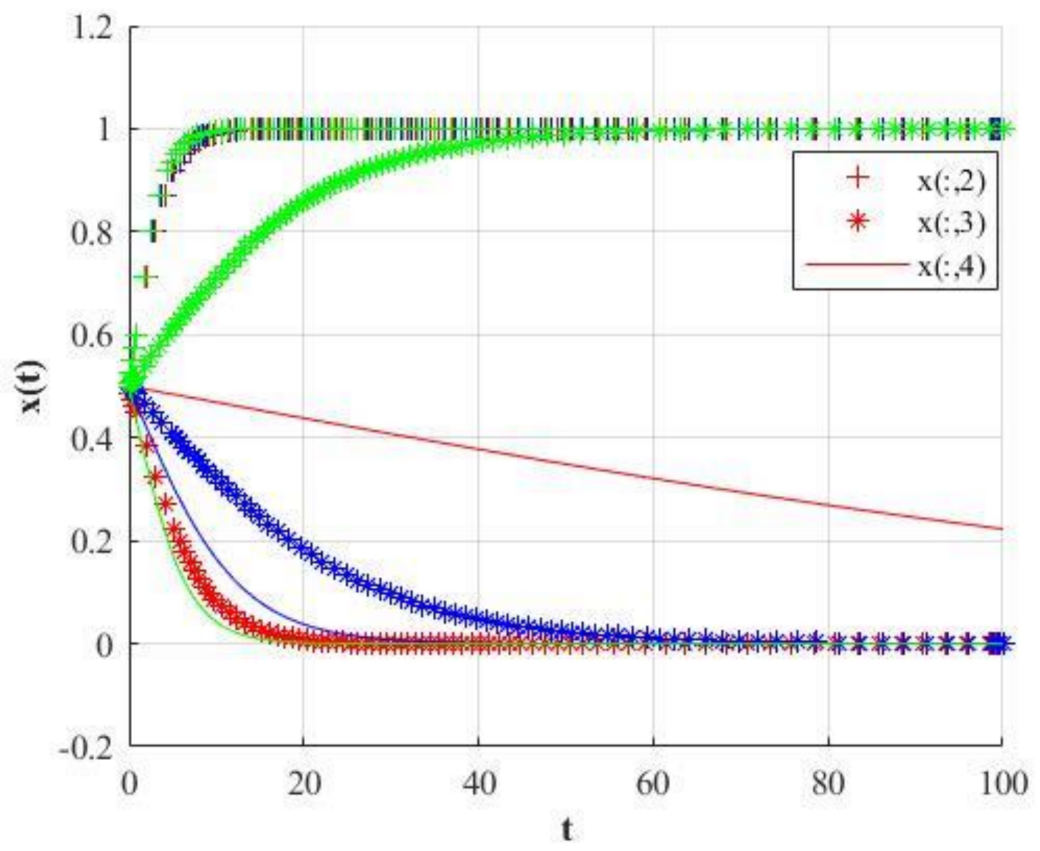

Figure 24. Change the parameter $\delta_{2}$ and $\delta_{3}$, and their values are $(0.8,0.2)$ (red curve), $(0.5,0.5)$ (blue curve), and $(0.2,0.8)$ (green curve) so as to take the value of the three-way strategy evolution diagram.

Compared with urging consumers to participate in the governance of live streaming, if the anchor's non-standardized performance can be controlled, it is equivalent to improving the problem of live streaming from the source. In addition, considering the large number of consumers and the wide range of discrimination capabilities, it is not easy to unify their opinions. It is difficult for government regulatory agencies to improve the live streaming environment from the consumer side, but it is easier to supervise top anchors. 


\subsection{Simulation Results}

The above simulations respectively simulate the evolution strategies of the evolutionary equilibrium points $(1,0),(1,1),(1,0,0)$ when the subject with social preferences and without social preferences, and the results show that:

(1) When the evolutionary equilibrium strategy of government and the live streaming platform is (supervision, non-standardized operation), i.e., the evolutionary equilibrium point is $(1,0)$, there are two situations that are conducive to the governance of the live streaming environment: 1) Strengthening government's reciprocal preference when platform holds egoism preference. 2) Strengthening government's altruistic preference when platform does not hold egoism preference;

(2) When the evolutionary equilibrium strategy of government and the live streaming platform is (supervision, standardized operation), i.e., the evolutionary equilibrium point is $(1,1)$, strengthening government's altruistic preference and weakening platform's altruistic preference can be used to improve live streaming governance;

(3) When the evolutionary equilibrium strategy of live streaming platform, anchor and consumer is (standardized operation, non-standardized behavior, non-guiding), i.e., the evolutionary equilibrium point is $(1,0,0)$, there are 4 situations that are conducive to governance of the live streaming environment: (1) Weakening platform's altruistic preference and strengthening consumer's altruistic preference can be used when anchor holds egoism preference. Improving the live streaming environment is mainly based on the participation of consumers in governance; therefore, consumers should participate in the guidance in a timely and effective manner, improve the undesirable phenomena of live streaming from the demand side, optimize the quality of products and content, and promote its standardized development; (2) strengthening anchor's altruistic preference may be applied when consumer holds egoism preference. At this time, anchor can still obtain quite number of profits from non-standardized behavior, who hardly change the altruistic preference. Therefore, this measure is more difficult to implement; (3) weakening platform's altruistic preference can be used to promote the anchor's behavioral strategy to standardized behavior when both anchor and consume hold egoism preference; (4) weakening platform's altruistic preference will help improve the anchor's bad behavior when three parties all hold egoism preferences. Meanwhile, compared with guiding consumers to participate in the governance of live streaming, restraint from the behavior of the top anchors will have a better effect.

\section{Discussion}

In this section, we will discuss three issues. Firstly, it introduces the practical application and management meaning of this study. Secondly, the findings of this paper are briefly compared with those of other cultures and geographical regions. Finally, the limitations of this study are discussed in detail.

\subsection{Practical Utilization and Managerial Implications}

In view of the online communication property of live streaming, most of the effective information exists in the online comments of major Internet platforms. That is, online comments contain a large number of emotional expressions of users. The existing literature uses questionnaire survey to obtain the required information, and its data sources are limited. The method of online comment data mining can help the government extract the information value hidden in the massive data, and find out the existing problems of live streaming, as well as the merchants or anchors who violate the rules for a long time, so as to grasp the focus of netizens and the pain points of live delivery, and put forward more targeted governance strategies and regulatory rules and regulations. If the government supervision department wants to test the governance effect in the later period, it can also use the method in this paper to re-analyze the comments of netizens, and learn about the social repercussions and effects in different periods of the live streaming governance by dynamically adjusting the measurement data. 
In this paper, the multi-agent cooperative governance game model is constructed, and its subjects come from Section 4 . In the past, the subjects in evolutionary game literature were obtained by qualitative analysis. However, in the process of actual governance evolutionary game, it is urgent to solve the negative subjects most mentioned by consumers, and dynamically adjust the subjects in the evolutionary game according to the actual governance effect. Therefore, according to the nature of the subject, the governance process in this study is divided into two stages, one is the governance promotion process with "government" as the key node, and the other is the transaction stage between buyers and sellers with "consumers" as the key node. In practical application, it is unnecessary to consider all relevant subjects. Models at different stages can be selected according to the current situation of live streaming, so as to reduce redundant items in the process of governance.

In Section 5, the social preference is incorporated to discuss the game process of multiple subjects collaborative governance. In practice, the "preference" in the study can be divided according to the occupation, education background, ages of the actual population or the emotional value of negative events of live streaming. According to the simulation results in this paper, different governance strategies are adopted for people with different preferences (see Tables 6 and 10 for specific measures), so as to achieve the best governance effect.

\subsection{Comparing with Other Cultures and Geographical Regions}

Affected by the epidemic, the form of live streaming will greatly promote the sales of domestic e-commerce. In overseas markets, we can see the obvious trend of media e-commerce, and their basic operation modes are the same. In this paper, the disadvantages and advantages of live streaming were discovered through online comment information. This method is also suitable for improving the problems existing in foreign e-commerce industry.

The rapid development of domestic live streaming cannot be separated from the comprehensive popularization of the Internet and efficient logistics express delivery. When analyzing consumers' comments, Chinese users pay more attention to product quality yet are not dissatisfied with express delivery efficiency very much. But as far as foreign countries are concerned, online shopping is relatively troublesome, with long logistics and transportation time, no relatively fixed express delivery point, no specific timeliness of product arrival, and high labor cost, which will lead to differences between foreign consumers' concerns and problems.

In order to promote economic recovery in the context of the epidemic, the Chinese government has given more supportive policies to the e-commerce industry. However, foreign governments have not participated in this industry too much and given corresponding assistance. Therefore, the game process of multi-agent collaborative governance in Section 5 is more in line with China's national conditions. If this method is to be applied to foreign e-commerce industry, it is necessary to adjust the types of agents, the gains and effects obtained in the game process.

This study considers the preferences of different subjects, which are based on the characteristics of Chinese consumers, while consumers of different regional cultures have different consumption characteristics. For example, in China, consumers' awareness of rights protection is low, and their altruistic preference degree has no obvious effect on governance; Moreover, Chinese consumers are sensitive to the price of products, which also causes vicious competition in China's e-commerce market. In contrast, Japanese consumers pay more attention to the quality of products, which will lead to different emphasis in the governance process of e-commerce media industry.

\subsection{Limitations of This Paper}

This study was mainly based on the development status of China's e-commerce industry with live broadcast goods, China's Internet popularity, China's transportation 
conditions, China's national conditions, and the characteristics of Chinese consumers, and explored the existing problems in the live broadcast goods industry. In addition, we discussed how to achieve the optimal governance effect through the multi-agent game process. However, there are differences in infrastructure conditions, national conditions, and consumption habits in different countries. To discuss the existing problems and governance strategies of e-commerce media industry as a whole, it is necessary to improve the data information in this paper and crawl the online comment information of e-commerce platforms at home and abroad [51].

In this study, there was no quantitative method of subject preference in real life. In the future study, subject preference can be divided in detail according to the user information of consumers, such as age, occupation, region, past consumption records, and emotional value of comment information, so as to make it closer to the actual management application.

\section{Conclusions}

This paper took the live streaming as an objective, and collected the comment information of netizens on "live streaming" from 19 May 2020 to 19 May 2021. By information entropy, co-occurrence matrix, and subject extraction, the paper extracts the key information from the comments, and used the repeated dichotomy to classify it by subject, so that netizens mentioned more issues and different subjects involved in the live streaming. In addition, it introduced the social preference theory to construct the evolution game model of live streaming in governance promotion stage and the transaction stage. The related simulation results showed that:

(1) Among the topics that people pay more attention to, five categories of stakeholders are mainly mentioned: the front-tier anchors (influential opinion leaders), government regulatory departments, brand(businesses), live streaming platforms, and consumers. The related topics of "live streaming" mainly focus on two aspects: (1) consumers' negative sentiments about the chaos in the existing live streaming industry, and (2) the affirmation that live streaming drives the rural industrial economy;

(2) In promotion stage or transaction stage, changing their altruistic preference is more beneficial to govern live streaming compared with strengthening reciprocal preference. In particular, weakening platform's altruistic preference can accelerate the development of the behavioral strategies of various subjects in a direction that is conducive to the governance of live streaming, e.g., strengthening the government's altruistic preference and weakening the platform's altruistic preference. It is conducive to the evolution and stability strategy of the government and the platform (supervision, standardized operation). Specific measures: The government can improve the platform's entry incentives, etc. As far as the platform is concerned, it can raise the cost standard for entering the platform, report the bad behaviors in the platform to the government in a timely manner;

(3) Compared with the influences of government and platform preference on the effect of live streaming governance, the influences of consumers' altruistic preference and reciprocal preference on improving the environment of live streaming are less important. If the anchor's non-standardized performance can be controlled, it is equivalent to improving the problem of live streaming from the source. It is difficult for government regulatory agencies to improve the live streaming environment from the consumer side, but it is easier to supervise top anchors.

Based on the above analysis and research, the following two suggestions are proposed, which are expected to optimize the live streaming environment:

(1) Government intensifies to govern live streaming industry

During the outbreak of the epidemic, in order to stimulate economic recovery, the government gives numerous supports to the live streaming industry, such as tax reductions and exemptions, house purchase incentives, and rent subsidies. At present, under the normal situation of epidemic prevention and control, the economy becomes normal. At this time, the requirement for the live streaming industry is not rapid development, but the 
healthy and high-quality development, which aims to fix various problems and continually make improvement.

(2) Play the role of live streaming platform

The above analysis of the governance of live streaming indicates that the platform can establish a credit evaluation system, a blacklist system, etc., reduce floating rewards for anchors who have more user reviews and complaints, and restrict their bad behaviors by reducing support and publicity.

Author Contributions: T.C. described the proposed framework and wrote the whole manuscript; L.P. implemented the simulation experiments; G.L. collected data; J.Y. and G.C. revised the manuscript. All authors have read and agreed to the published version of the manuscript.

Funding: This research was supported by the National Social Science Foundation of China (Grant No. 20BTQ059).

Institutional Review Board Statement: Not applicable.

Informed Consent Statement: Informed consent was obtained from all subjects involved in the study.

Data Availability Statement: The data used to support the findings of this study are available from the corresponding author upon request.

Conflicts of Interest: The authors declare that they have no competing interests.

\section{References}

1. Enrico Santarelli Samuele, D.A. The Diffusion of E-commerce among SMEs: Theoretical Implications and Empirical Evidence. Small Bus. Econom. 2003, 21, 273-283. [CrossRef]

2. Shi, Y. A Study on the Influence of E-commerce Live Streaming on Consumer's Purchase Intentions in Mobile Internet. In Proceedings of the International Conference on Human-Computer Interaction, Copenhagen, Denmark, 19-24 July 2020.

3. Hou, F. The Chance of China's Cross Border E-commerce in Coronavirus Pneumonia Epidemic. Reg. Educat. Res. Rev. 2020, 2, 26. [CrossRef]

4. Liu, Y.L. Research on the New Trend in E-Commerce Industry: Mobile E-Commerce. Adv. Mater. Res. 2014, 23, $2635-2637$. [CrossRef]

5. Chen, T.; Peng, L.; Yang, J.; Cong, G. Analysis of User Needs on Downloading Behavior of English Vocabulary APPs Based on Data Mining for Online Comments. Mathematics 2021, 9, 1341. [CrossRef]

6. Chen, T.; Rong, J.; Peng, L.; Yang, J.; Cong, G.; Fang, J. Analysis of Social Effects on Employment Promotion Policies for College Graduates Based on Data Mining for Online Use Review in China during the COVID-19 Pandemic. Healthcare 2021, 9, 846. [CrossRef]

7. Wang, X.L. Research on the Impact of Internet Celebrity Live Broadcasting on Consumers' Purchase Intention Based on Hierarchical Regression Analysis. Theor. Res. 2020, 49, 76-80. (In Chinese)

8. Liu, Z.Y.; Zhao, X.H.; Long, W. The Formation Mechanism of Consumers' Purchase Intention under the Live Broadcasting in online celebrity -Based on grounded theory. China Bus. Market 2020, 34, 48-57. (In Chinese)

9. Sun, Y.; Shao, X.; Li, X.; Guo, Y.; Nie, K. How live streaming influences purchase intentions in social commerce: An IT affordance perspective. Electr. Commer. Res. Appl. 2019, 37, 1-12. [CrossRef]

10. Apiradee, W.; Nuttapol, A. The role of live streaming in building consumer trust and engagement with social commerce sellers. J. Bus. Res. 2018, 32, 1-14.

11. Addo, P.C.; Fang, J.; Asare, A.O.; Kulbo, N.B. Customer engagement and purchase intention in live-streaming digital marketing platforms. Serv. Indust. J. 2021, 19, 1-22.

12. Jiang, Y.; Cai, H. The impact of impact consumption on supply chain in the live-streaming economy. IEEE Access 2021, 9 48923-48930. [CrossRef]

13. Apiradee, W.; Nassim, D.; Nuttapol, A. Live streaming commerce from the sellers' perspective: Implications for online relationship marketing. J. Market. Manag. 2020, 5, 1-31.

14. Li, Y.; Li, X.; Cai, J. How attachment affects user stickiness on live streaming platforms: A socio-technical approach perspective. J. Retail. Consum. Serv. 2021, 60, 1-9. [CrossRef]

15. Ma, Y. To shop or not: Understanding Chinese consumers' live-streaming shopping intentions from the perspectives of uses and gratifications, perceived network size, perceptions of digital celebrities, and shopping orientations. Telem. Inform. 2021, 59, 1-17.

16. Zeng, Y.X.; He, F. Characteristics Analysis and Standardized Governance of China's Webcast Industry. Res. Lib. Sci. 2017, 38, 57-60. (In Chinese)

17. Xia, L.; Lin, H.; Huang, N.; Li, J. Risk analysis of College Student's e-commerce live broadcast based on data in survey. J. Phys. Conf. Ser. 2021, 7, 1-7. 
18. Yan, Y.G.; Gong, C.B. Carnival and De-carnival-Cold Thinking Based on the Phenomenon of Live Broadcasting with Goods during the COVID-19 Epidemic. Contemp. TV 2020, 34, 94-97. (In Chinese)

19. Huang, W. An Analysis of the Live Commerce Business Model. Front. Econom. Manag. 2021, 5, 227-233.

20. Hou, F.J. Analysis on the Development Trend of E-commerce Live Streaming. Learn. Educat. 2020, 9, $194-195$.

21. Xia, L.L.; Song, J. Standardization of "Live Broadcasting with Goods" in Post-epidemic Era. Theor. Explor. 2020, 36, 94-96. (In Chinese)

22. Li, Y.B.; Zhang, J.R. The Evolutionary Game of Webcast Governance Strategies. Econom. Manag. 2020, 34, 25-31. (In Chinese)

23. Chen, T.; Rong, J.; Yang, J.; Cong, G.; Li, G. Combining Public Opinion Dissemination with Polarization Process Considering Individual Heterogeneity. Healthcare 2021, 9, 176. [CrossRef] [PubMed]

24. Chen, T.; Yin, X.; Peng, L.; Rong, J.; Yang, J.; Cong, G. Monitoring and Recognizing Enterprise Public Opinion from High-Risk Users Based on User Portrait and Random Forest Algorithm. Axioms 2021, 10, 106. [CrossRef]

25. An, X.Y.; Wu, Q. Co-word analysis of the trends in stem cells documented based on subject heading weighting. Scientmetrics 2011, 33, 133-144. [CrossRef]

26. Gerard, S.; Christopher, B. Term-weighting approaches in automatic text retrieval. Inf. Proc. Manag. 1988, 24, 513-523.

27. David, N.; Yakir, A.; Hilary, K.; Sharon, R.; Gilean, M.V.; Peter, J.; Eric, S.; Michael, M.; Pardis, C. Detecting Novel Associations in Large Data Sets. Science 2011, 334, 1518-1524.

28. Li, L.; Liu, J.; Zhang, H.K. Research on Topic Discovery and Situation Evolution of Internet Public Opinion Based on Co-occurrence Analysis. Inf. Sci. 2016, 34, 44-47. (In Chinese)

29. Zhang, Y.Y.; Tang, L.N.; Liu, Y. Rural Functional Zoning and Revitalization Ways in the Beijing-Tianjin-Hebei Region. Econm. Geogr. 2020, 40, 161-167. (In Chinese)

30. Zhou, Y.A. On the Microstructure of Preference. South China J. Econom. 2015, 32, 106-115. (In Chinese)

31. Ye, H.; Wang, D.D.; Luo, W.D. Altruistic Behavior as Endogenous Preference and Its Economic Significance. Econom. Res. J. 2005, 50, 84-94. (In Chinese)

32. Yang, C.X. Pursuit of altruistic economics. Econom. Res. J. 2001, 46, 82-90. (In Chinese)

33. Jiang, W.J.; Yan, T.W.; Zhang, J.B. Decision Choice and Policy Enlightenment of Farmers with Different Preferences on Straw Disposal-Based on the Perspective of Evolutionary Game. Chinese J. Agric. Res. Region 2020, 41, 1-13. (In Chinese)

34. Rabin, M. A Perspective on Psychology and Economics. Eur. Econom. Rev. 2002, 46, 657-685. [CrossRef]

35. Camerer, C. Behavioral Game Theory: Experiments on Strategic Interaction; Princeton University Press: Princeton, NJ, USA, 2003; pp. $167-188$.

36. Ortona, G.; Ottone, S.; Ponzano, F.; Scacciati, F. Labour supply in presence of taxation financing public services. An experimental approach. POLIS Work Pap. 2006, 29, 619-631.

37. Chen, Y.; Ye, H.; Wang, D. Beyond the theory of social preference of economic man: A summary based on experimental economics. Nankai Econom. Stud. 2012, 7, 63-100. (In Chinese)

38. Ashley, E.A.; Ferrara, R.; King, J.Y.; Vailaya, A.; Kuchinsky, A.; He, X.M.; Byers, B. Network Analysis of Human In-Stent Restenosis. Circulation 2006, 114, 2644-2654. [CrossRef]

39. Andreoni, J.; Miller, J. Giving According to GARP: An Experimental Test of the Consistency of Preferences for Altruism. Econometrica 2002, 70, 737-753. [CrossRef]

40. Thiel, H.; Thomsen, S.L. Noncognitive skills in economics: Model, measurement, and empirical evidence. Res. Econom. 2013, 67, 9-76. [CrossRef]

41. Chen, Y.F. Prosocial behavior and the decomposition of social preferences. Econom. Res. J. 2009, 54, 132-145. (In Chinese)

42. Chen, Y.F.; Ye, H.; Wang, D.D. Measurement of trust level and its influence on cooperation-Evidence from a group of experimental microscopic data. Manag. World 2010, 24, 54-64. (In Chinese)

43. Gintis, H.; Wang, X. Evolutionary Game Theory: A Problem-Oriented Strategy Interaction Model; China Renmin University Press: Beijing, China, 2015.

44. Charness, G.; Rabin, M. Understanding social preferences with simple tests. Quart. J. Econom. 2002, 117, 817-869. [CrossRef]

45. Kohler, S. Difference Aversion and Surplus Concern an Integrated Approach; European University Institute: Florence, Italy, 2003.

46. Fehr, E.; Schmidt, K.M. A theory of fairness, competition, and cooperation. Quart. J. Econom. 1999, 114, 817-868. [CrossRef]

47. Friedman, D. Evolutionary Games in Economics. Econometrica 1991, 59, 637-666. [CrossRef]

48. Xu, X.B.; Li, H.; Shi, F. Research on Supply Chain Coordination under Multiple Social Preferences. J. Syst. Manag. 2017, 26, 154-162. (In Chinese)

49. Rabin, M. Incorporation fairness into game theory and economics. Am. Econom. Rev. 1993, 83, 1281-1320.

50. Levine, D.K. Modeling altrusim and spitefulness in experiments. Rev. Econom. Dyn. 1998, 1, 593-622. [CrossRef]

51. Chen, T.; Peng, L.; Yin, X.; Jing, B.; Yang, J.; Cong, G.; Li, G. A Policy Category Analysis Model for Tourism Promotion in China During the COVID-19 Pandemic Based on Data Mining and Binary Regression. Risk Manag. Healthc. Policy 2020, 13, 3211-3233. [CrossRef] [PubMed] 